\title{
Re-Evaluating the Climate Factor in Agricultural Land Assessment in a Changing Climate-Saskatchewan, Canada
}

\author{
Samantha A. Kerr ${ }^{1,2}{ }^{*}$, Yuliya Andreichuk ${ }^{1}$ and David J. Sauchyn ${ }^{1,2}$ \\ 1 Prairie Adaptation Research Collaborative (PARC), University of Regina, Regina, SK S4S 7J7, Canada; \\ andreici@uregina.ca (Y.A.); sauchyn@uregina.ca (D.J.S.) \\ 2 Department of Geography and Environmental Studies, University of Regina, Regina, SK S4S 0A2, Canada \\ * Correspondence: SamanthaKerr@uregina.ca
}

Received: 13 February 2019; Accepted: 15 March 2019; Published: 19 March 2019

\begin{abstract}
We established the statistical relationships between seasonal weather variables and average annual wheat yield (Hard Red Spring and Durum wheat: Triticum spp.) for the period of 1979-2016 for 296 rural municipalities (RMs) throughout six soil zones comprising the arable agricultural zone of Saskatchewan, Canada. Controlling climate variables were identified through Pearson's product moment correlation analysis and used in stepwise regression to predict wheat yields in each RM. This analysis provided predictive regression equations and summary statistics at a fine spatial resolution, explaining up to $75 \%$ of the annual variance of wheat yield, in order to re-evaluate the climate factor rating in the arable land productivity model for the Saskatchewan Assessment and Management Agency (SAMA). Historical climate data (1885-2016) and Regional Climate Model (RCM) projections for the growing season (May-August) were also examined to put current climatic trends into longer-term perspective, as well as develop a better understanding of possible future climatic impacts on wheat yield in Saskatchewan. Historical trends demonstrate a decrease in maximum temperature and an increase in minimum temperature and precipitation throughout all soil zones. RCM projections also show a potential increase in temperatures and total precipitation by $5{ }^{\circ} \mathrm{C}$ and $10 \%$, respectively. We recommended against a modification of the climate factor rating at this time because (1) any increase in wheat yield could not be attributed directly to the weather variables with the strongest trends, and (2) climate and wheat yield are changing more or less consistently across the zone of arable land, and one soil zone is not becoming more productive than another.
\end{abstract}

Keywords: agriculture; Canadian Prairies; climate change; climate projections; land values; regression analysis; Saskatchewan; wheat yield

\section{Introduction}

Saskatchewan, one of the Canadian Prairie provinces, has approximately $42 \%$ of Canada's cropland [1]. More than half of Canadian farms are located within the Canadian Prairie provinces, where more than 32,000 farms seed and produce wheat in Saskatchewan alone [1]. In 2016, wheat exports of approximately $\$ 3$ million CAD represented two of the top ten exports for Saskatchewan [2]. This area is vulnerable to a variable hydroclimate and the resulting year-to-year variation of differences in agricultural production of crops and livestock is due to weather [3]. This study provides an evaluation of the influence of several climatic variables on wheat (Triticum spp.) yield over Saskatchewan's arable agricultural zone (Figure 1). The recognition of significant climate change in this region prompted a re-evaluation of the role of the climate in the assessment of the value of agricultural land. 


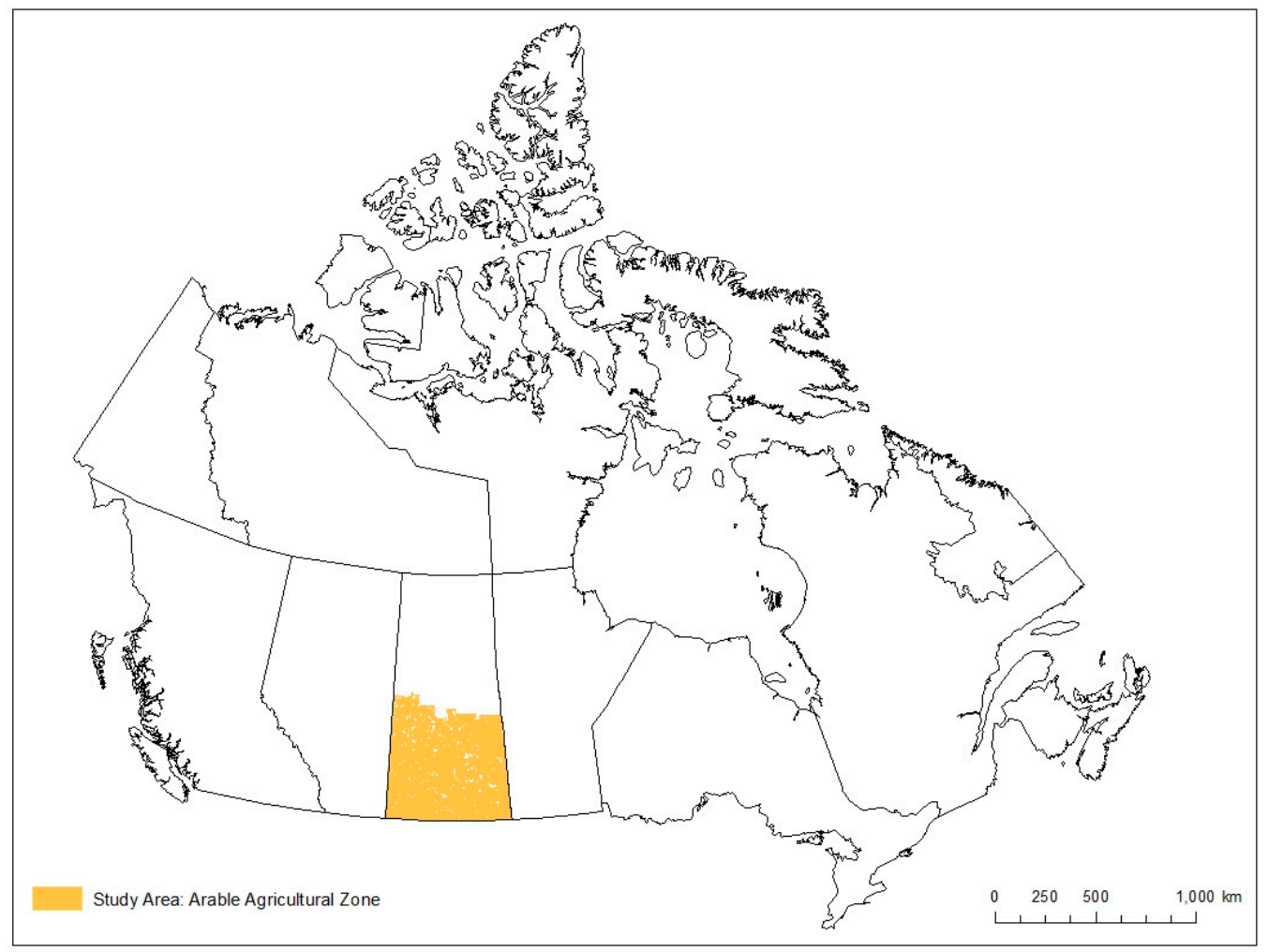

Figure 1. Study area: Saskatchewan's arable agricultural zone.

Saskatchewan's climate is characterized by short, hot summers and long, cold winters. Annual precipitation is low (approximately $300-500 \mathrm{~mm}$ ), but most of it occurs during the growing season in the spring and summer months. It follows a southwest to northeast gradient, where the southwest is much drier. Crop yields are limited by the generally dry climate but also sensitive to climatic variability and extreme weather, including heat waves, drought, frost, minimum and maximum temperatures, plough winds, hail, and excess moisture. Continuous snow cover throughout the winter months is essential as water supply and early summer moisture depends on the snowmelt.

Since the settlement of the Prairie provinces, agricultural production has adapted to the highly variable and cyclical climatic conditions of this semiarid region [4]. Crop production in Saskatchewan has thus become much more diversified with an increase in pulse crops (i.e., peas, lentils), soybeans, and corn [5]. Crop production data from 2005 to 2016 show an increase in the average yield, and this trend is consistent with projections of higher crop yields in a warming climate [6,7]. Research suggests that crop producers could benefit from a warming climate $[5,8]$, provided that agricultural practices and policies can be adapted to withstand increased climatic variability $[9,10]$. Climate model projections show warming temperatures increased precipitation (i.e., in the amount and timing, as well as the form), but also increased evapotranspiration, which will result in decreased summer soil moisture $[4,11,12]$. Also, an increase in the number of frost-free days (FFD) and growing degree days (GDD) could improve Prairie wheat crop production as well as reduce the number of days between seeding and harvest seasons [13]. Rising temperature could also, however, be favorable for pests, disease, and weeds [14]. Thus, research on the degree to which crop productivity varies with climate has taken on a new relevance with concerns about the impacts of global climate change on food security [5]. Ultimately, this potential for increased productivity implies rising values of Saskatchewan's arable land.

The Saskatchewan Assessment and Management Agency (SAMA) is an independent provincial government agency within Saskatchewan that provides property assessment valuations as a basis for tax policy and property tax rates [15]. There is a reassessment of land values every five years. For rural 
Saskatchewan, SAMA uses an arable land model to determine the assessed value of agricultural land according to ratings of climate, soil characteristics, and physical, economic, and regional factors. Climate is a major factor in their model. The climate rating varies by rural municipality (RM) according to soil zone, accounting for the relationship between climate and soil productivity. Further description of the methodology and calculations that SAMA uses can be found at: https://www.sama.sk.ca/ property-owner-services/understanding-assessment/methods-assessment.

Significant changes in crop diversity (i.e., pulse crops, soybeans, corn, etc.) and production [5], as well as the climate of the Canadian Prairie provinces $[9,16]$, warranted a re-evaluation of the climate factor in SAMA's arable land productivity model, and a potential reassessment of property values. Current climate ratings are based on 1973-1989 climatic and wheat yield data [17]. Hard Red Spring and Durum wheat crops were selected for this analysis, as they continue to be produced extensively throughout the agricultural region of Saskatchewan. Production of wheat yield has increased from 1979 to 2016 under a changing climate. If Saskatchewan farms produce more yield per hectare per year with the changing climate, the assessed value of that farm land should ultimately change. However, awareness of the potential effects of a changing climate on crop yields first requires an understanding of how specific crops respond to the natural hydroclimatic variability of the region [18]. While there is research on the prediction of crop yield through complex numerical modeling [8,19-24], this was not the purpose of this research.

Therefore, the primary objective of this research was to determine whether recent climate changes are associated with significant trends in crop productivity and, in turn, agricultural land values in Saskatchewan's arable agricultural zone, and to understand how these trends have varied over space and time. Any significant change in climate and wheat yields would thus necessitate a change in the climate factor rating for SAMA's arable agricultural productivity model. Neither SAMA, the land assessment agency, nor the researchers quantitatively define significant changes. We collaboratively evaluated the changes in climate and yield in the context of projected further climate changes, and according to whether the rates were (1) consistent across the agricultural landscape or differed among soil zones, and (2) attributable to natural variability in the regional hydroclimatic regime.

\section{Materials and Methods}

The geographic sampling unit for this research was the RMs of Saskatchewan. The study area, as depicted by the RM boundaries, is shown in Figure 1. The use of high-resolution geographic data sets enables accurate estimations of wheat yield in Saskatchewan's arable agricultural zone, capturing the spatial variation and influence of climate change.

\subsection{Soil Data}

Soil zone data (Figure 2) were provided by SAMA. The six major soil zones within the arable agricultural zone of Saskatchewan are Dry Brown, Moist Brown, Dark Brown, Black, Orthic Gray, and Dark Gray. These soil zones are identified by soil surface color, which is determined by the organic matter type and content within the soil. The Brown, Dark Brown, Black, and Dark Gray soil zones are based upon the Canadian System of Soil Classification (CSSC) color criteria for the great groups of the Chernozemic soil order, while the Orthic Gray soil zone is based upon CSSC color criteria of the Luvisolic soil order. Soil zones are the best spatial representation of regional climate zones, since each type of soil has developed under a distinct temperature and precipitation regime, as well as vegetation conditions. Since there is a general decrease in annual precipitation from the northeast to the southwest, there is also a corresponding decline in productivity from the Black to Dark Brown to Dry Brown soils. This soil information for the province allows for the analysis of climate-driven variation in soil and crop productivity at high spatial resolution. 


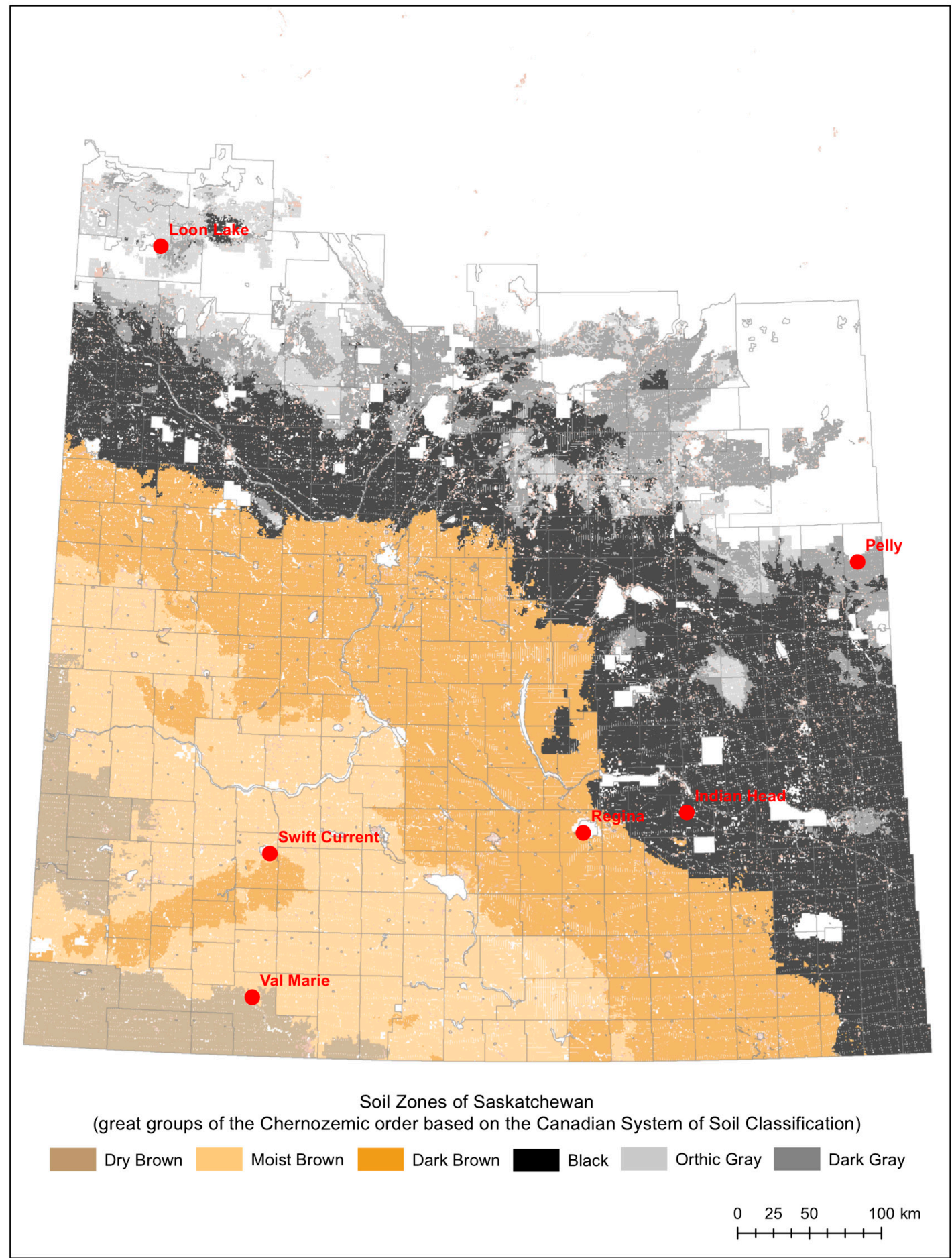

Figure 2. Soil zones, rural municipalities (RMs), and selected weather stations (in red) within southern Saskatchewan.

\subsection{Weather Data}

Confidential weather station data for 1979-2016 were provided by Information Systems Management (ISM) Canada from the Weather Company for 714 weather stations computed by nearest-neighbor interpolation with 30-km (km) spatial resolution (Figure 3). From this large monthly data set of total precipitation, average, minimum, and maximum temperature, and potential evapotranspiration (PET), annual and seasonal values were computed for each station and the difference in trends (1979-2016) were documented. Thirty-eight years of weather records do not fully represent the natural variability 
of the climate system, so in addition to this interpolated data set, historical records (1885-2016) from Environment and Climate Change Canada's Adjusted and Homogenized Canadian Climate Data (AHCCD) [25] were used to determine the long-term trends and natural variability of minimum and maximum temperatures and total precipitation for the growing season throughout the six soil zones prior to 1979. While there will be differences among the climate stations throughout the soil zones, within each of the six soil zones, we selected the longest and most complete record for a single weather station, as averaging climatic data smooths the natural variability and extremes. The selected stations were: Swift Current, Regina, Indian Head, Val Marie, Loon Lake, and Pelly (Figure 2, Table 1).

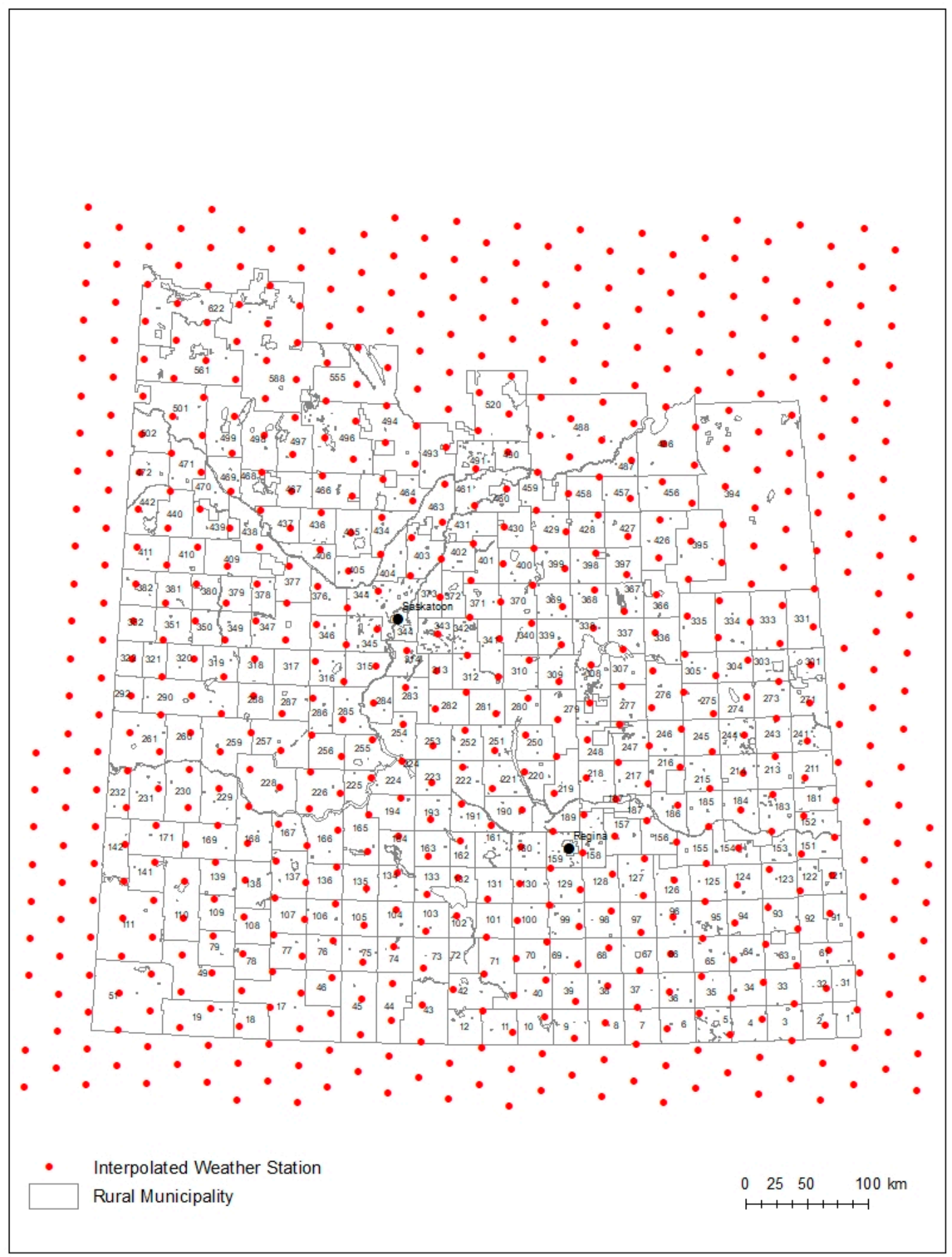

Figure 3. Interpolated weather station (1979-2016) network and rural municipality (RM) boundaries. 
Table 1. Historical weather station information.

\begin{tabular}{ccccc}
\hline Station Name & Latitude $\left({ }^{\circ} \mathbf{N}\right)$ & Longitude $\left({ }^{\circ} \mathbf{W}\right)$ & Length of Record & Soil Zone \\
\hline Val Marie & 49.37 & -107.85 & $1937-2010$ & Dry Brown \\
Swift Current & 50.27 & -107.73 & $1885-2017$ & Moist Brown \\
Regina & 50.43 & -104.67 & $1898-2017$ & Dark Brown \\
Indian Head & 50.55 & -103.65 & $1889-2017$ & Black \\
Loon Lake & 54.02 & -109.13 & $1930-2017$ & Orthic Gray \\
Pelly & 52.08 & -101.87 & $1951-2016$ & Dark Gray \\
\hline
\end{tabular}

Ten km gridded daily weather data (1950-2010) compiled by Natural Resources Canada (ANUSPLIN) [26] were also used to compute historical trends in growing degree days (GDDs) and frost-free days (FFDs). While this record provides complete and uniform coverage of daily climatic data for North America, minimum and maximum temperatures are smoothed as a result of interpolation [27]. Both GDDs and FFDs were computed for the grid point closest to the AHCCD historical weather station. GDDs are a measure of accumulated heat over a period of time, and are calculated as the difference between an average of minimum and maximum temperature, as well as a base temperature that is required for plant growth (i.e., minimum temperature for wheat to grow is $5{ }^{\circ} \mathrm{C}$ ). FFDs, on the other hand, are a measure of the number of days between the average last date of $0^{\circ} \mathrm{C}$ in the spring and the average first date of $0{ }^{\circ} \mathrm{C}$ in the fall.

\subsection{Crop Yield Data}

Confidential detailed crop yield data for 1973-2016 were provided by the Saskatchewan Crop Insurance Corporation (SCIC). Saskatchewan crop yield data by RM are also publicly available at http: / / www.agriculture.gov.sk.ca/rmyields. Crop yield data were converted from bushels per acre (bu/ac) to metric tons per hectare ( $\mathrm{t} / \mathrm{ha})$ using the appropriate conversion factor $(1 \mathrm{bu} / \mathrm{ac}=0.06725 \mathrm{t} / \mathrm{ha})$. A time series of average wheat yield $(t / h a)$ for 1973-2016 is plotted in Figure 4. In general, wheat yields have been increasing over time throughout Saskatchewan's arable agricultural zone, and in the last five years, wheat yields have been higher than they have ever been. There is a noticeable pattern from the southwest to the northeast, where the average yield is greater towards the northeast. The Brown and Dark Brown soil zones show similar trends in terms of average wheat yield, while the Black and Gray soil zones are also comparable to each other.

\subsection{Relationship of Wheat Yield to Climate}

Using the RM boundaries as the geographical sampling unit, interpolated weather stations were assigned to each of the RMs by first calculating the centroid of each RM polygon, then determining the closest weather station using a buffer of approximately $30 \mathrm{~km}$. Then, interpolated weather data were extracted and averaged for 1979-2016. Next, statistical relationships between wheat yield and climate were determined through Pearson's product moment correlation analysis using the variables listed in Table 2.

The correlation of average annual wheat yield ( $t / h a)$ to annual and seasonal precipitation and temperature variables was analyzed by RM within each of the six soil zones to identify climatic controls of wheat yield. Significant positive correlation $(p<0.05)$ between yield and growing season precipitation was highest in the semiarid Brown soil zone, and decreased throughout the Dark Brown and Black soil zones. It was not significant in the region of Gray soils. Significant negative correlation $(p<0.05)$ with temperature during the summer months reflects the detrimental effect of midsummer hot, dry weather on wheat yields (i.e., when crops are exposed to heat and moisture stress), except for the Gray soil zones. 


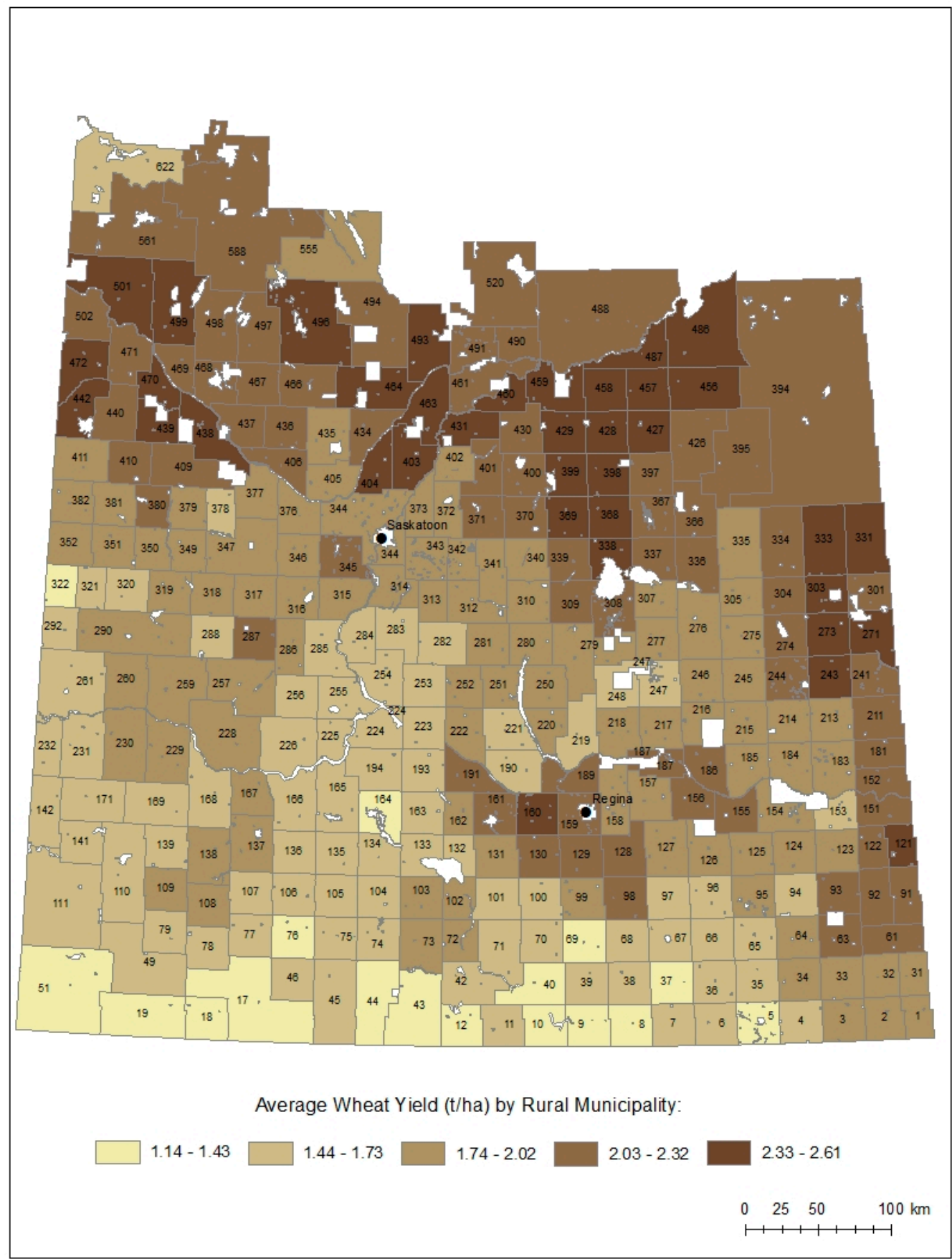

Figure 4. Average wheat yield (t/ha) by rural municipality (RM) (1979-2016).

Regression models of average annual wheat yields (1979-2016) with historical interpolated seasonal climate were created for Saskatchewan's arable agricultural zone by RM. Initial exploratory analysis revealed that regression equations at this fine scale, compared to a larger geographic area (i.e., soil zone, results not shown), were better predictors of average annual wheat yield. At the larger scale, where climate and yield data were averaged over the soil zone level, the influence of temperature was lost, and precipitation became the dominant predictor of wheat yield for most RMs. Overall, at the scale of RMs, both temperature and precipitation were significant predictors of average annual wheat yield, and the deviations of predicted from observed wheat yields were smaller than when using regression models based on soil zones.

While the validity of the regression models for all 296 RMs confirms that weather is the dominant determinant of annual wheat yield, the maximum variance of $75 \%$ explained by weather variables 
reflects the influence of other factors such as local topography and soil conditions, disease and pests, storm damage, and changes in farming practices (i.e., discontinuing use of summer fallow) [28]. While simple regression gave reasonable predictions of wheat yield, these statistical models are not numerical crop models, that is, they are not intended to be predictors of crop yields derived from an understanding of the environmental and physiological processes that sustain and limit plant productivity $[14,29]$.

Table 2. Climatic variables legend for correlation analysis and regression equations *

\begin{tabular}{c}
\hline Temperature $\left({ }^{\circ} \mathrm{C}\right)$ \\
Average monthly temperature ${ }^{\text {a }}$ \\
Average spring (March, April, May) temperature \\
Average summer (June, July, August) temperature \\
Average maximum temperature (spring \& summer) \\
Average minimum temperature (spring \& summer) \\
\hline Precipitation (mm)
\end{tabular}

Total monthly precipitation ${ }^{b}$

Total spring (March, April, May) precipitation

Total summer (June, July, August) precipitation

* From interpolated weather station data. ${ }^{\text {a }}$ Average monthly temperature: averages for January through December.

$\mathrm{b}$ Total monthly precipitation: totals for January to December.

Regression equations were thus developed to establish the influence of climate on wheat yields over 38 years and 296 RMs, using the stepwiselm function in MATLAB R2016b (MathWorks ${ }^{\circledR}$ ). Climatic variables that were significantly $(p<0.05)$ correlated with wheat yield represented a pool of potential predictors. Linear stepwise regression is an iterative application of forward selection and backward elimination [30]. The dependent variable is wheat yield ( $t / h a)$, and the resulting equation for each $R M$ is a unique set of independent climatic variables, representing the climatic controls on wheat yield ( $t / h a)$ in a given RM. Using the stepwise regression methodology, after a variable is added to the model, any nonsignificant (below the threshold of $95 \%$ ) variable is removed. Therefore, backward elimination removed redundant variables from the model [30].

Yield regression models were evaluated by comparing the model-predicted yields to the observed yield over the 38-year period of 1979-2016 using goodness-of-fit measures: the coefficient of determination $\left(R^{2}\right)$ and the root mean square error (RMSE). The coefficient of determination $\left(R^{2}\right)$ is a measure of the proportion of the total variance in the observed data shared with the predictors in the model, ranging from 0 to 1 , where values closer to 1 indicate a better agreement between the observed and predicted data. Regression equations accounted for approximately 20 to $75 \%$ of annual variation in wheat yield. Because $\mathrm{R}^{2}$ values can be highly sensitive to outliers in data sets, the RMSE was also used to evaluate the model performance. The RMSE is a measure of the average differences between predicted and observed values, providing an estimate of model error in the units of the variable (i.e., wheat yield). The sum of squared errors (SSE) was computed for each unique regression equation as a measure of variance. The SSE is a unitless value calculated from the sum of squared deviation, or difference between the observed and predicted values. SSE values ranged from 4.52 to 17.49 throughout the six soil zones (Dry Brown: 4.52-8.90, Moist Brown: 5.01-10.75, Dark Brown: 5.28-13.74, Black: 6.03-15.97, Orthic Gray: 8.14-16.06, and Dark Gray: 9.12-17.49). For example, RM \#17 (Table 3) within the Dry Brown soil zone had the highest goodness of fit $\left(R^{2}\right)$ and the lowest variance (SSE), indicating that this model best fits the observed data with minimum variance for the soil zone. The RMSE and SSE are important measures of statistical precision due to both variance and outliers in the data. F and $p$-values also were used to verify the statistical significance of the regression analysis. The regression models did not include more than four predictors per equation, limiting the risk of overfitting the models. 
Table 3. RM-based regression equation statistics for selected RMs (one per soil zone).

\begin{tabular}{|c|c|c|c|c|c|c|c|c|c|}
\hline Soil Zone & RM \# & Regression Equation * & $\begin{array}{l}\text { Average Yield } \\
(\mathrm{t} / \mathrm{ha})\end{array}$ & $\begin{array}{l}\text { Predicted } \\
\text { Yield (t/ha) }\end{array}$ & $\mathbf{R}^{2}$ & RMSE & SSE & F-Stat & $p$-Value \\
\hline Dry Brown & 17 & $\mathrm{y}=-0.621+0.007\left(\mathrm{spr} \_\right.$pr) $+0.005($ sum_pr $)$ & 1.352 & 1.355 & 0.74 & 0.36 & 4.52 & 49.70 & $5.94 \times 10^{-11}$ \\
\hline Moist Brown & 46 & 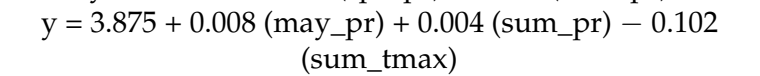 & 1.436 & 1.445 & 0.68 & 0.41 & 5.76 & 24.26 & $1.41 \times 10^{-8}$ \\
\hline Dark Brown & 100 & $\mathrm{y}=2.884-0.112($ jul_t $)+0.004($ jun_pr $)+0.005($ spr_pr $)$ & 1.717 & 1.724 & 0.62 & 0.39 & 5.29 & 18.50 & $2.73 \times 10^{-7}$ \\
\hline Black & 469 & $\mathrm{y}=6.016+0.006($ sum_pr $)-0.156($ sum_tmax $)$ & 2.286 & 2.309 & 0.57 & 0.53 & 9.95 & 23.26 & $3.76 \times 10^{-7}$ \\
\hline Orthic Gray & 499 & $\mathrm{y}=6.335+0.005($ sum_pr $)-0.174($ sum_tmax $)$ & 2.136 & 2.160 & 0.55 & 0.55 & 10.75 & 21.20 & $9.30 \times 10^{-7}$ \\
\hline Dark Gray & 501 & $\mathrm{y}=8.580-0.229$ (sum_tmax $)+0.172$ (spr_tmin) & 2.318 & 2.337 & 0.49 & 0.59 & 12.05 & 16.94 & $7.14 \times 10^{-6}$ \\
\hline
\end{tabular}

* spr_pr: total spring precipitation; sum_pr: total summer precipitation; may_pr: total May precipitation; jun_pr: total June precipitation; sum_tmax: average maximum summer temperature; spr_tmin: average spring minimum temperature; and jul_t: average July temperature. 
In Table 3, the best RM-based regression equations and summary statistics are provided for one RM per soil zone. Differences in the climate determinants of wheat yield demonstrate the hydroclimatic gradients throughout Saskatchewan's arable agricultural zone over time, with the prominent southwest to northeast gradient of lower temperatures and greater precipitation and the transition in soil zones. Correlation and regression results indicate the importance of growing season (spring and summer months) precipitation and temperature variables as predictors of wheat yield.

\subsection{Climate Projections of Precipitation and Temperature Variables}

For climate projections, we used output from an ensemble of seven Regional Climate Models (RCMs) from the North American domain of the Coordinated Regional Climate Downscaling Experiment (NA-CORDEX). All RCMs were forced with RCP 8.5, which is a high-emissions pathway. Raw monthly data for minimum (tasmin) and maximum (tasmax) temperatures and precipitation (pr) for 2021-2100 were extracted from NetCDF files for North America. For temperature variables, units were converted from $\mathrm{K}$ to ${ }^{\circ} \mathrm{C}$, and precipitation values were converted from $\mathrm{kg} / \mathrm{m}^{2} / \mathrm{s}$ to $\mathrm{mm} / \mathrm{month}$. Leap years were taken into consideration when converting $\mathrm{mm} /$ day to $\mathrm{mm} / \mathrm{month}$. Next, grid points below $55^{\circ} \mathrm{N}$ within the provincial boundary of Saskatchewan were selected. Growing season (May-August) mean tasmin, tasmax, and total pr were calculated for each grid point, and then averaged over the agricultural zone for each model separately. Raw data were not bias-corrected, as we were only comparing future and historical simulations, and presumably they were subject to the same degree of bias.

\section{Results}

\subsection{Climate Data}

Temperature and precipitation trends have changed throughout all soil zones from 1979 to 2016. Table 4 gives the direction of change from trends over 38 years for each weather variable by soil zone, and over Saskatchewan's arable agricultural zone, computed as the difference between 2016 and 1979 trend values. Throughout the six soil zones, the average standard error (SE) for mean, maximum, and minimum temperature trends fell between 1.13 and 4.30 (i.e., annual: 1.23-1.95, growing season: 1.13-1.66, and winter: 1.59-4.30). The average SE for total precipitation trends was 104.60 (annual), 72.61 (growing season), and 30.93 (winter). The average SE for mean, maximum, and minimum PET trends fell between 0.06 and 5.54 (i.e., annual: 0.06-3.12, growing season: 0.08-5.54, and winter: 0.13-0.72). The most apparent change in climatic trends is an increase in minimum temperatures, especially in winter. The statistical relationships between weather and wheat yield do not include minimum winter temperature as a correlate or predictor. This may change, however, as winter continues to get warmer and thus shorter in terms of the length of the frost-free period and growing season. The amount of warming is greatest in the Black and Gray soil zones. Thus, the climate of Saskatchewan is warming by becoming much less cold, rather than hotter. Maximum temperatures, especially in the growing season, have actually declined. This could be the result of more humid conditions and increased precipitation (high summer temperatures are associated with dry, clear conditions). These documented climate changes from trends are generally favorable for crop production, as the decrease in maximum temperatures should expose crops to less heat and moisture stress.

There is also an upward trend in precipitation in all soil zones since 1979. While wetter conditions are consistent with a warming climate, the results of our analysis of precipitation over the past several decades should be interpreted with caution. The continental climate of western Canada is characterized by large variability in precipitation from year to year and decade to decade. The time series analyzed here starts with a dry decade (the 1980s) and ends with the relatively wet conditions of the past decade. This decadal variability could be a factor in the upward trends observed over the past several decades. Results from this analysis also show a decrease in PET for all soil zones over all time periods, which coincides with decreasing trends of evaporation (E) and PET across the 
Canadian Prairies [31]. Our research agrees with Gameda et al. (2007), who found significant decreases in maximum temperature and increasing precipitation during June and July for the Black, Dark Brown, and Brown soil zones of the Canadian Prairies [32].

Table 4. Summary of climatic change from trends by soil zone and Saskatchewan's arable agricultural zone (1979-2016).

\begin{tabular}{|c|c|c|c|c|c|c|c|c|}
\hline $\begin{array}{l}\text { Time } \\
\text { Period }\end{array}$ & $\begin{array}{c}\text { Climate } \\
\text { Variable * }\end{array}$ & $\begin{array}{c}\text { Dry } \\
\text { Brown }\end{array}$ & $\begin{array}{l}\text { Moist } \\
\text { Brown }\end{array}$ & $\begin{array}{c}\text { Dark } \\
\text { Brown }\end{array}$ & Black & $\begin{array}{l}\text { Orthic } \\
\text { Gray }\end{array}$ & $\begin{array}{l}\text { Dark } \\
\text { Gray }\end{array}$ & $\begin{array}{l}\text { Arable } \\
\text { Agricultural Zone }\end{array}$ \\
\hline \multirow{9}{*}{ Annual } & $\mathrm{T}_{\text {mean }}$ & 0.1 & 0.0 & 0.0 & 0.2 & 0.3 & 0.2 & 0.2 \\
\hline & $\mathrm{T}_{\max }$ & -1.2 & -1.3 & -1.5 & -1.5 & -1.2 & -1.3 & -1.3 \\
\hline & $\mathrm{T}_{\min }$ & 0.7 & 0.9 & 1.1 & 1.2 & 1.4 & 1.3 & 1.5 \\
\hline & Total P & 235 & 275 & 300 & 273 & 177 & 203 & 225 \\
\hline & $\mathrm{PET}_{\text {mean }}$ & -2.05 & -2.44 & -2.54 & -2.30 & -1.53 & -1.76 & -1.94 \\
\hline & $\mathrm{PET}_{\max }$ & -6.05 & -7.06 & -7.24 & -7.24 & -5.97 & -6.53 & -6.29 \\
\hline & $\mathrm{PET}_{\min }$ & -0.18 & -0.15 & -0.15 & -0.14 & -0.13 & -0.12 & -0.13 \\
\hline & $\mathrm{GDD}^{* *}$ & 2.7 & 8.5 & 5.5 & 5.2 & -1.0 & 3.8 & 5.6 \\
\hline & FFD ** & 2.7 & 8.6 & 3.8 & 2.3 & -2.1 & 8.3 & 8.1 \\
\hline \multirow{7}{*}{$\begin{array}{l}\text { Growing } \\
\text { Season }\end{array}$} & $\mathrm{T}_{\text {mean }}$ & -0.8 & -1.1 & -1.3 & -1.1 & -0.5 & -0.6 & -0.8 \\
\hline & $\mathrm{T}_{\max }$ & -2.1 & -2.6 & -3.2 & -3.5 & -2.6 & -2.9 & -2.8 \\
\hline & $\mathrm{T}_{\min }$ & 0.9 & 1.0 & 0.9 & 1.4 & 1.3 & 1.2 & 1.2 \\
\hline & Total P & 165 & 192 & 211 & 206 & 142 & 162 & 169 \\
\hline & $\mathrm{PET}_{\text {mean }}$ & -4.17 & -5.14 & -5.68 & -5.22 & -3.11 & -3.72 & -4.25 \\
\hline & $\mathrm{PET}_{\max }$ & -10.51 & -12.57 & -14.28 & -14.02 & -9.81 & -11.30 & -11.59 \\
\hline & $\mathrm{PET}_{\text {min }}$ & -0.23 & -0.20 & -0.24 & -0.26 & -0.18 & -0.20 & -0.21 \\
\hline \multirow{7}{*}{ Winter } & $\mathrm{T}_{\text {mean }}$ & 0.1 & 0.3 & 0.6 & 0.5 & 0.6 & 0.5 & 0.7 \\
\hline & $\mathrm{T}_{\max }$ & -2.4 & -2.1 & -1.1 & -0.7 & -0.3 & -0.3 & -0.9 \\
\hline & $\mathrm{T}_{\min }$ & 0.6 & 1.3 & 1.9 & 1.7 & 2.3 & 1.9 & 2.4 \\
\hline & Total P & 8.0 & 20.0 & 23.0 & 14.0 & -6.0 & -1.0 & 7.0 \\
\hline & $\mathrm{PET}_{\text {mean }}$ & -0.65 & -0.46 & -0.17 & -0.10 & -0.03 & -0.05 & -0.16 \\
\hline & $\mathrm{PET}_{\max }$ & -5.28 & -4.07 & -2.07 & -1.33 & -0.68 & -0.75 & -1.77 \\
\hline & $\mathrm{PET}_{\text {min }}$ & -0.10 & 0.04 & 0.07 & 0.04 & 0.01 & -0.01 & 0.02 \\
\hline
\end{tabular}

${ }^{*} \mathrm{~T}_{\text {mean }}=$ mean temperature $\left({ }^{\circ} \mathrm{C}\right) ; \mathrm{T}_{\max }=$ mean maximum temperature $\left({ }^{\circ} \mathrm{C}\right) ; \mathrm{T}_{\min }=$ mean minimum temperature $\left({ }^{\circ} \mathrm{C}\right) ;$ Total $\mathrm{P}=$ total precipitation $(\mathrm{mm}) ; \mathrm{PET}_{\text {mean }}=$ mean PET $(\mathrm{mm}) ; \mathrm{PET}_{\max }=$ mean maximum PET $(\mathrm{mm}) ; \mathrm{PET}_{\min }=\mathrm{mean}$ minimum PET (mm). ** Growing degree days (GDDs) and frost-free days (FFDs) were calculated for 1950-2010.

Therefore, because we examined only 38 years of climate data, the interpretation of the climatic changes from trends by soil zone should be done so with caution. The trends we see in the shorter climate record for this current analysis (1979-2016) coincide with the upward part of a natural cycle in the regional hydroclimate. Longer instrumental records for Saskatchewan (1885-2016) show increasing trends in growing season minimum temperatures and a decreasing trend in growing season maximum temperatures, and emphasize the natural variability of precipitation over the length of a longer historical instrumental record. Figures 5 and 6 are plots of minimum and maximum growing season temperatures for 1885-2016 for the six soil zones. Figure 7 is a plot of growing season total precipitation for 1885-2016 for the six soil zones. The trends of GDDs and FFDs for 1950-2010 are presented in Figures 8 and 9, respectively. A summary of these climatic trends by soil zone and by Saskatchewan's agricultural zone is also provided in Table 4. There is an increase in GDDs and FFDs for all soil zones except for the Orthic Gray soil zone, although there is a relatively small area of Gray soil in the agricultural zone, and thus, much less weather station data. This longer climate time series demonstrates the importance of a long-term perspective, which in this case, shows a consistent warming trend but also natural decadal scale cycles. 


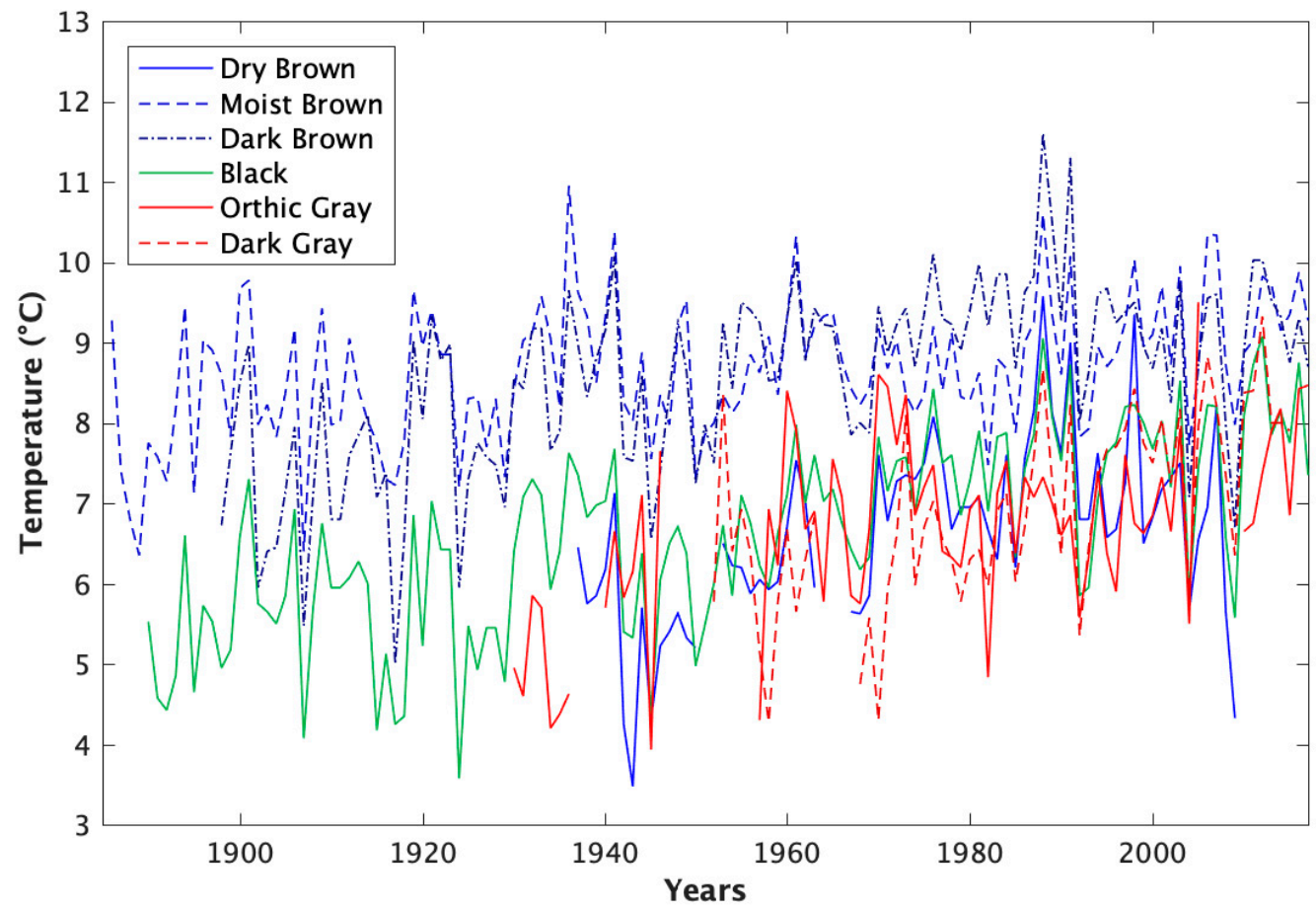

Figure 5. Growing season (May-August) minimum temperature $\left({ }^{\circ} \mathrm{C}\right)(1885-2016)$ for all soil zones.

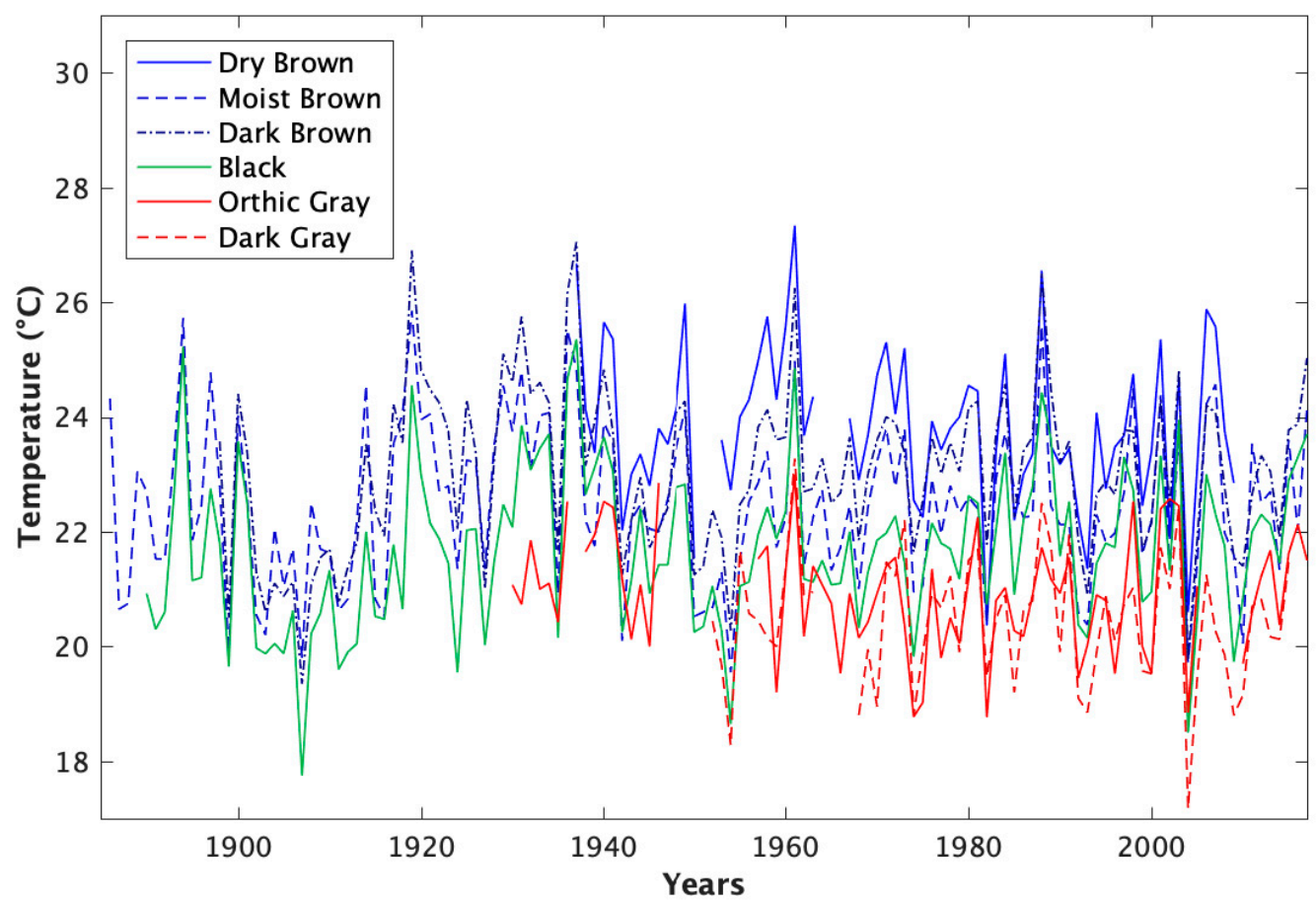

Figure 6. Growing season (May-August) maximum temperature $\left({ }^{\circ} \mathrm{C}\right)(1885-2016)$ for all soil zones. 


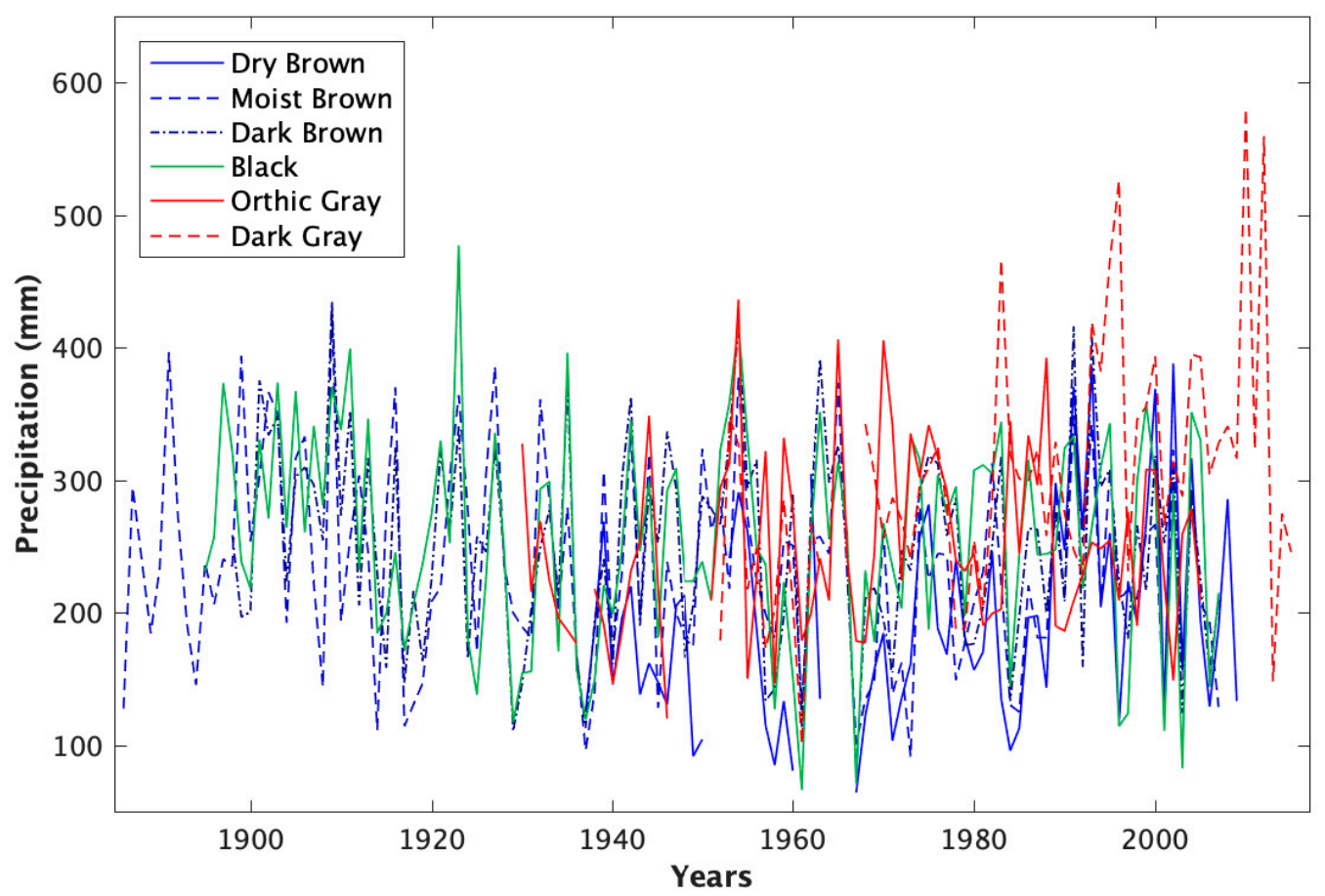

Figure 7. Growing season (May-August) total precipitation (mm) (1885-2016) for all soil zones.

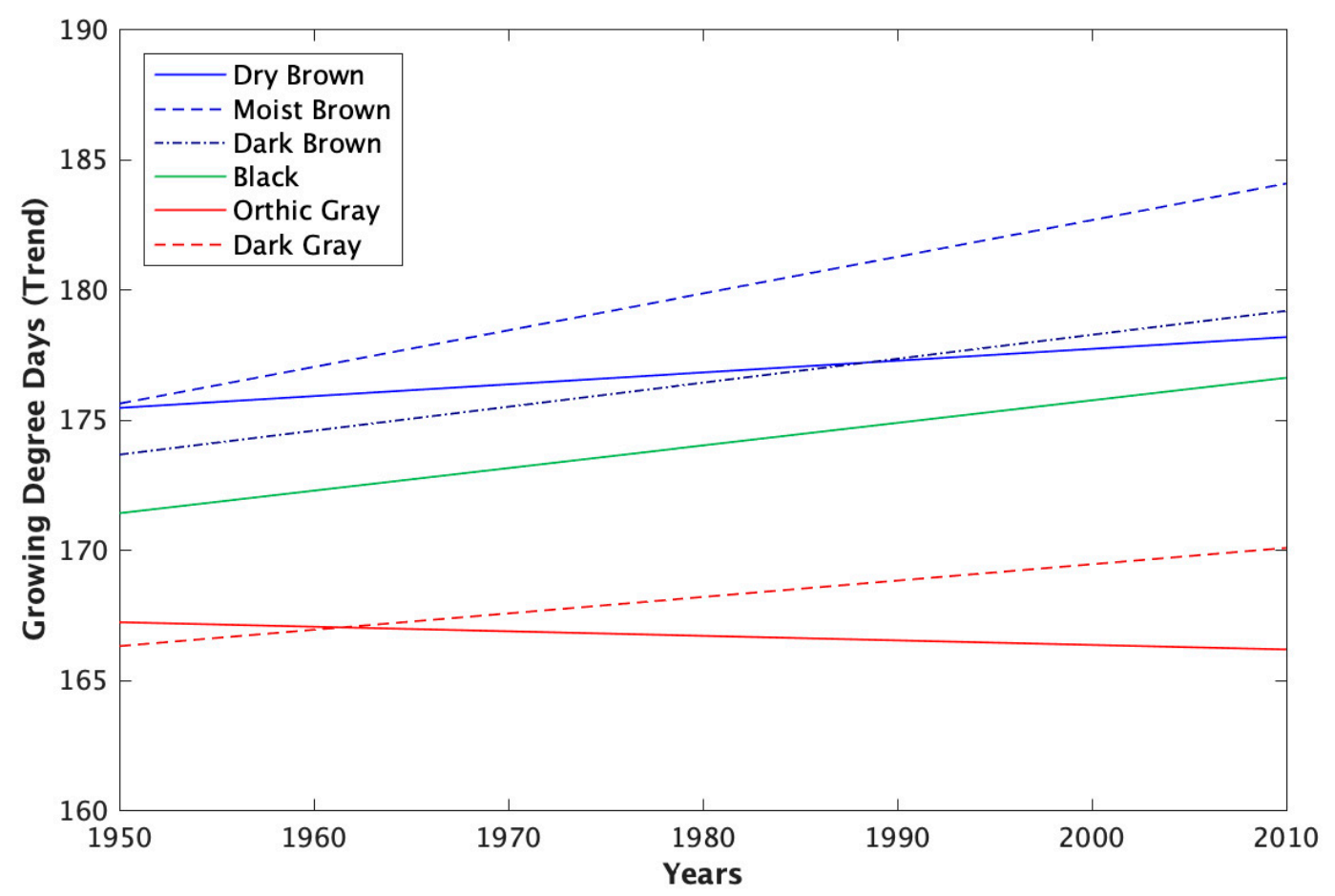

Figure 8. Growing degree days (GDDs) trend (1950-2010) for all soil zones. 


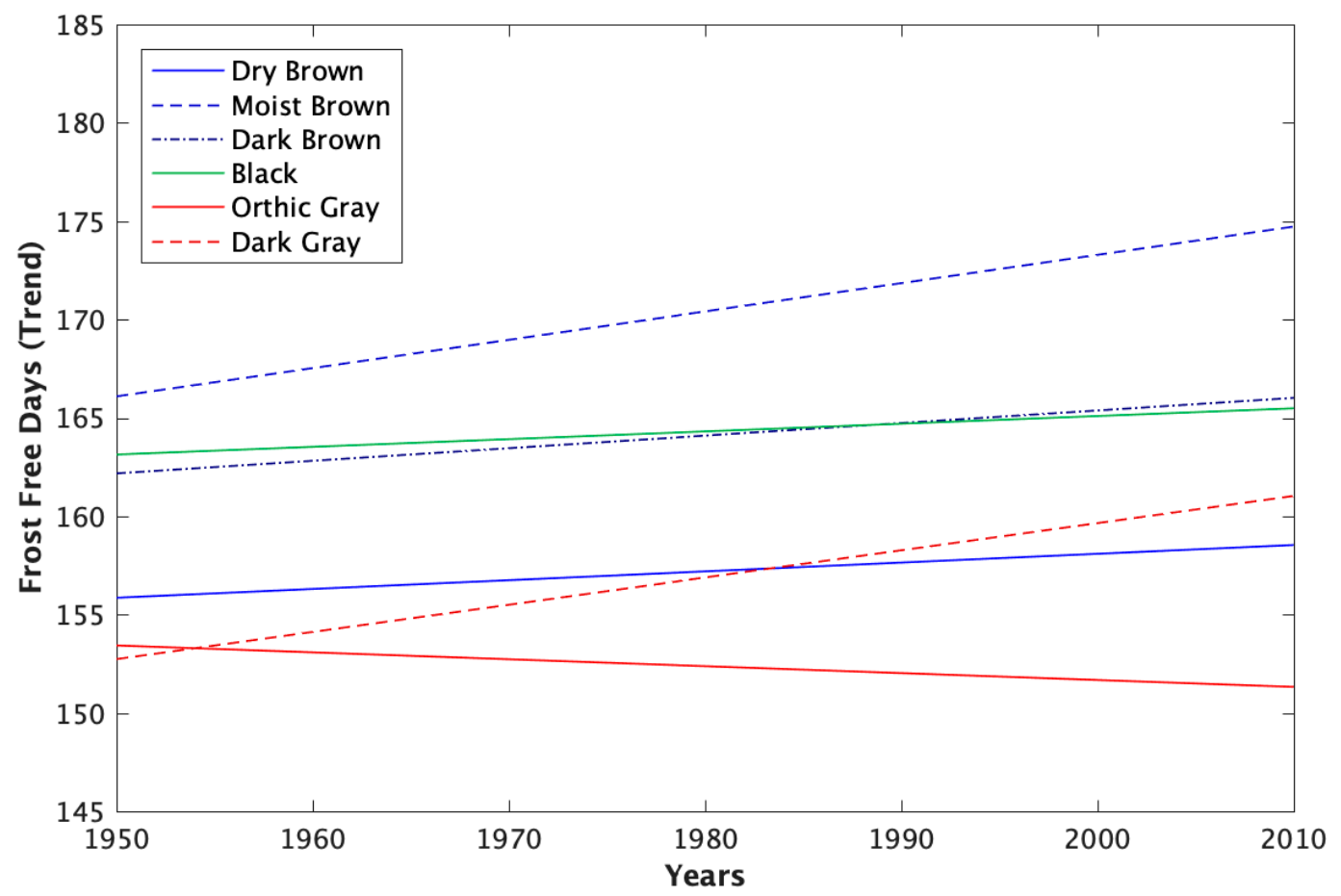

Figure 9. Frost free days (FFDs) trend (1950-2010) for all soil zones.

\subsection{Wheat Yield}

Figure 10 shows the average wheat yield predicted by the regression equations by RM for 1979-2016. Figure 11 is a map of the percent difference between average measured and predicted wheat yield for 1979-2016. These differences, which ranged between $-6 \%$ and 5\%, were categorized as minimal underestimates (less than or equal to $-1 \%$ ), minimal overestimates (greater than or equal to $1 \%$ ), and negligible differences (between $-1 \%$ and $1 \%$ ). Figures $12-17$ are time series of average and predicted wheat yield (1979-2016) for specific RMs. They are further valid indication that climate is a major determinant of wheat yield. Increases not explained by climate are likely due to improved farming practices. In Figure 12 through Figure 17, there tends to be an overestimate of yield during drought years (i.e., 1984-1985). Linear regression overestimates yield in dry years due to the nonlinear response of yield to precipitation below a certain level, which in some instances can result in crop failure, that is, zero yield.

Summer precipitation, followed by spring precipitation and maximum summer temperature, has had the strongest influence on wheat yield across Saskatchewan's arable agricultural zone for 1979-2016. Table 3 gives the regression equations and summary statistics. For each example provided, the model predictors are characteristic of the soil zones and follow a southwest to northeast gradient. For the Dry Brown soil zone, crop yield was heavily influenced by spring and summer precipitation. In the Moist Brown soil zone, crop yields were also predicted by spring and summer precipitation, but also summer temperature. In the Dark Brown soil zone, maximum summer temperature had a negative effect on crop yield. The main climatic controls on wheat yield in the Black soil zone were summer and maximum summer temperature. Minimum and maximum spring temperatures also influenced wheat yield in several RMs within the Black soil zone. For the Orthic and Dark Gray soil zones, the main controlling climatic variables on wheat yield included maximum summer temperature and summer precipitation. 


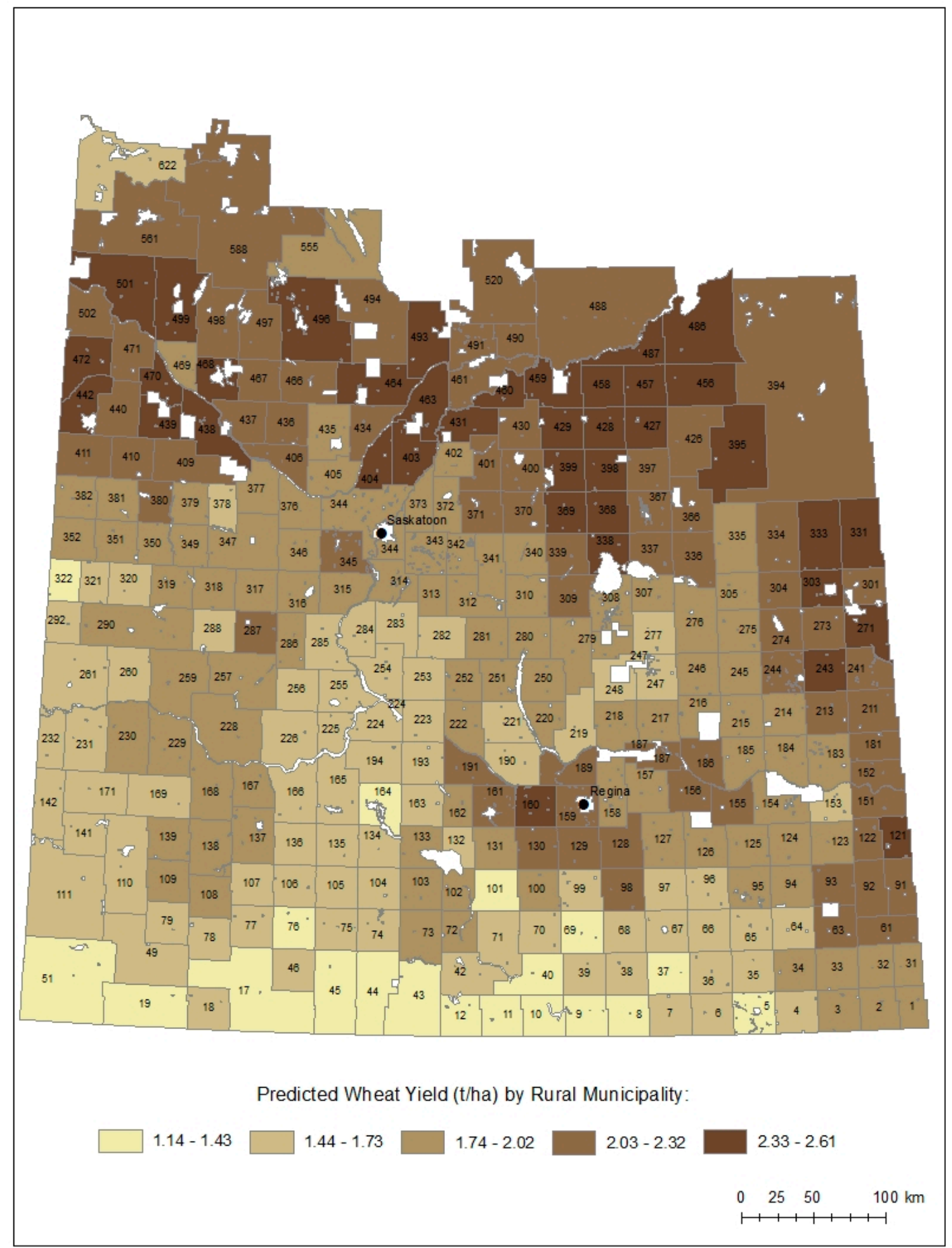

Figure 10. Predicted wheat yield (t/ha) by rural municipality (RM) (1979-2016). 


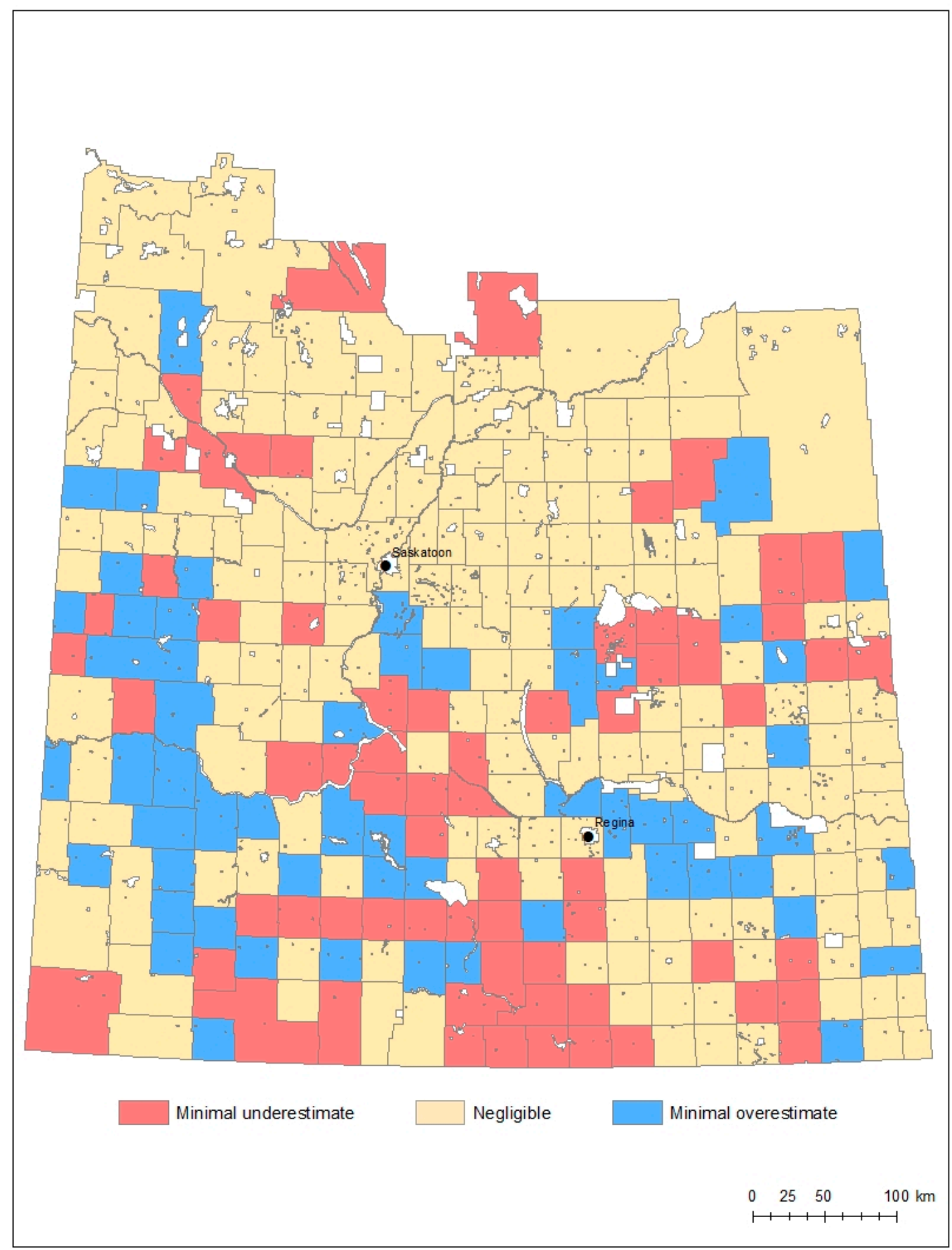

Figure 11. Percent difference between average and predicted wheat yield by rural municipality (RM) (1979-2016). 


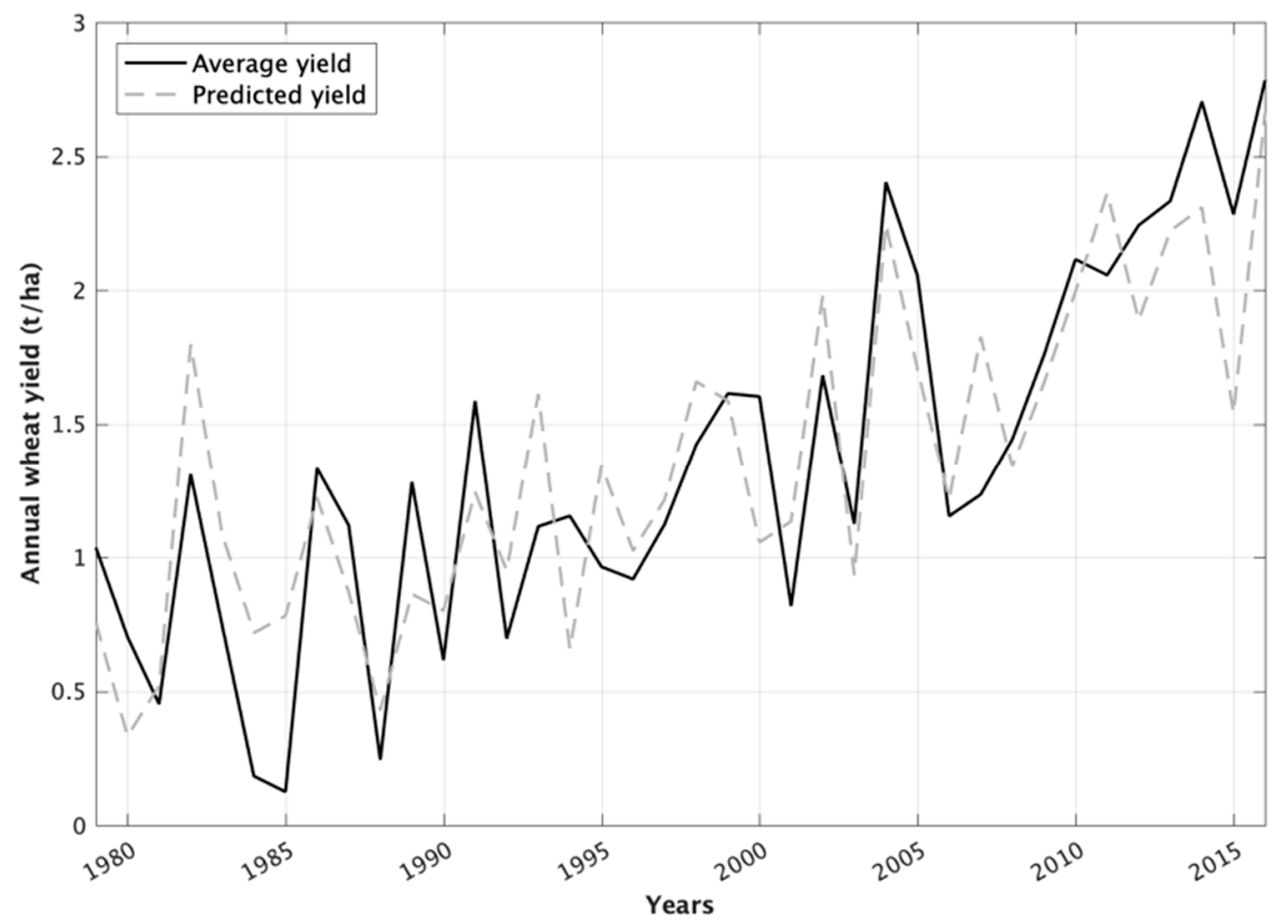

Figure 12. Average vs. predicted wheat yield for rural municipality \# 17 (1979-2016) (Dry Brown soil zone).

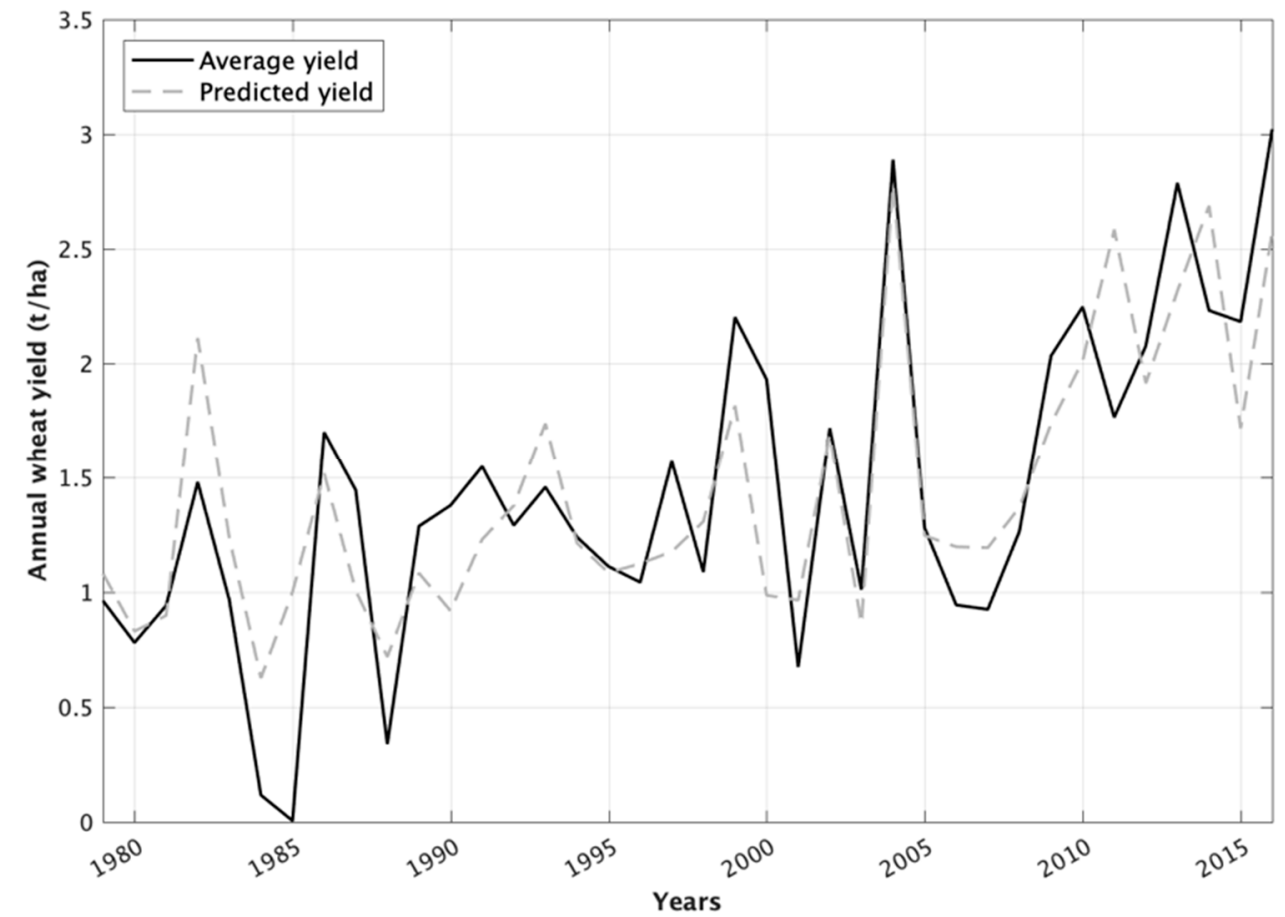

Figure 13. Average vs. predicted yield for rural municipality \# 46 (1979-2016) (Moist Brown soil zone). 


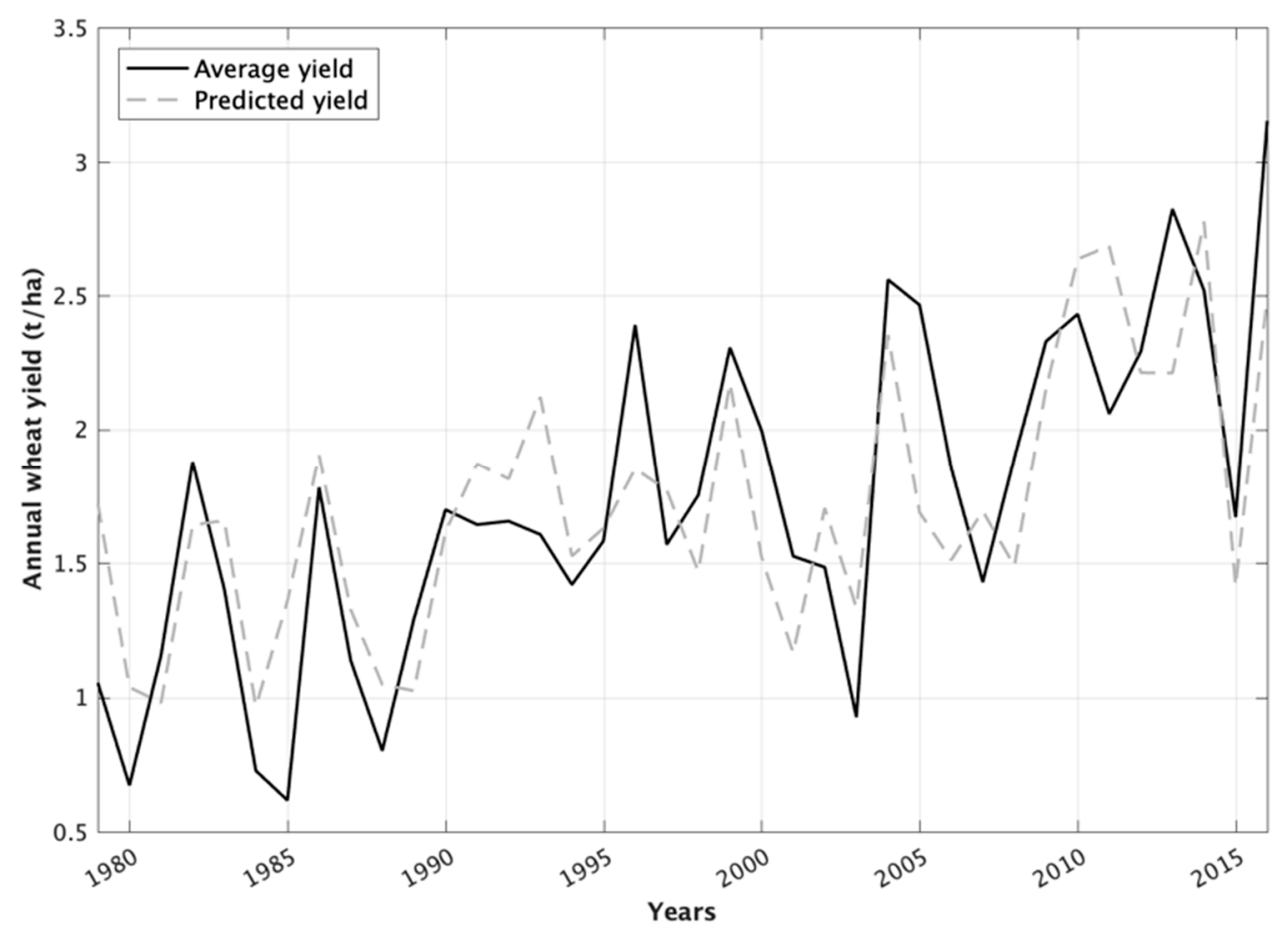

Figure 14. Average vs. predicted yield for rural municipality \# 100 (1979-2016) (Dark Brown soil zone).

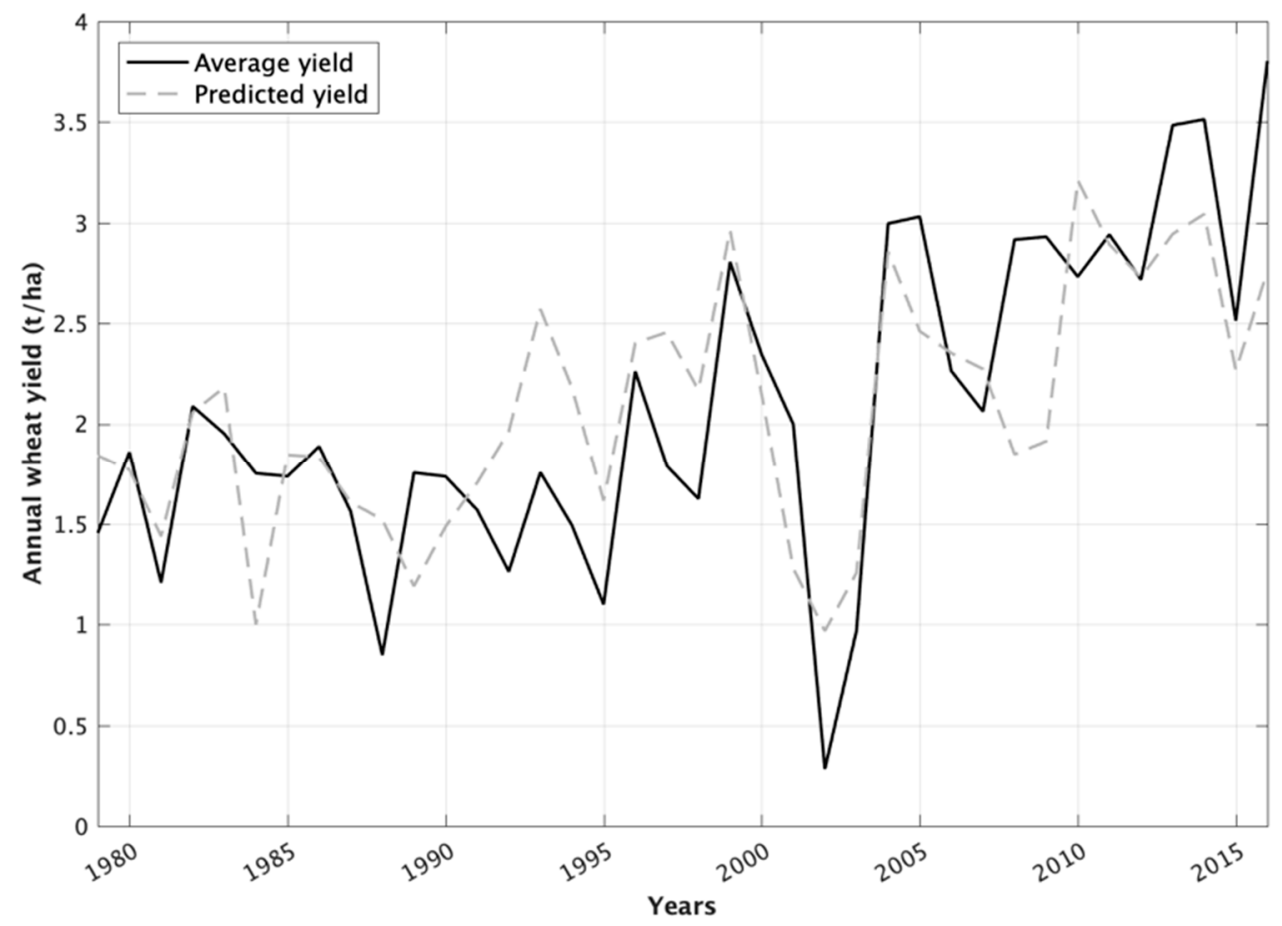

Figure 15. Average vs. predicted yield for rural municipality \# 469 (1979-2016) (Black soil zone). 


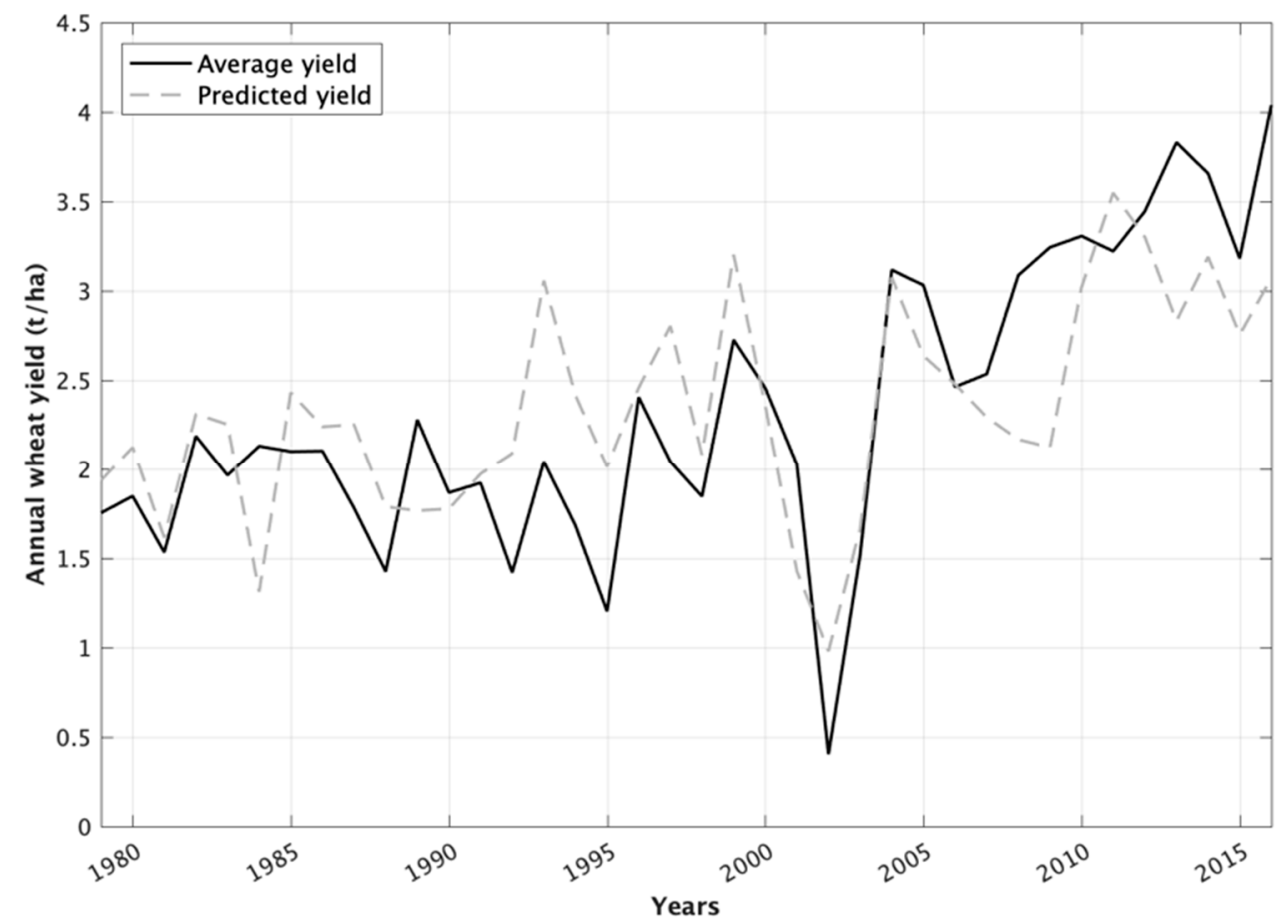

Figure 16. Average vs. predicted yield for rural municipality \# 499 (1979-2016) (Orthic Gray soil zone).

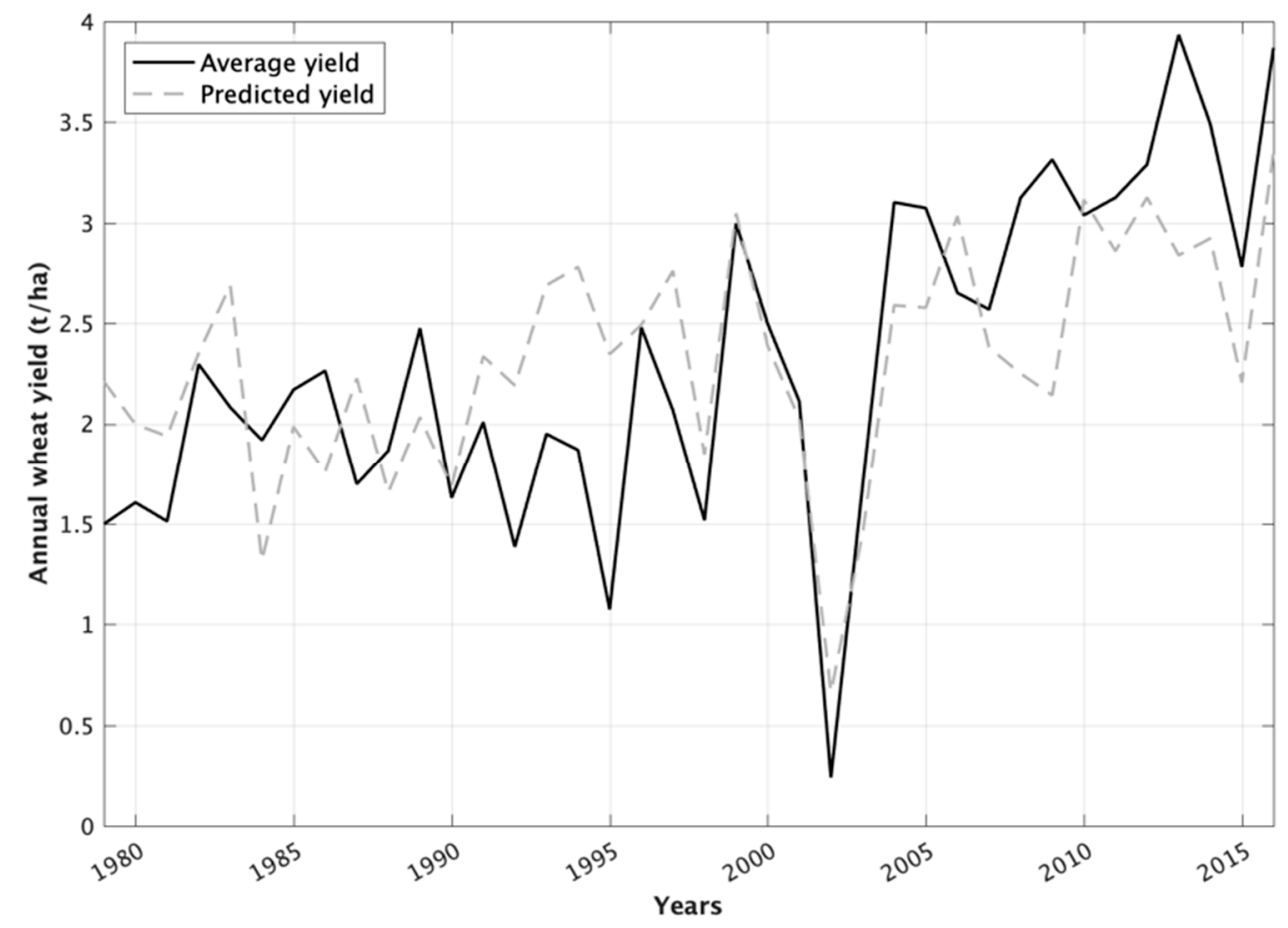

Figure 17. Average vs. predicted yield for rural municipality \# 501 (1979-2016) (Dark Gray soil zone).

\subsection{Climate Projections}

Figures 18 and 19 are scatterplots of projected changes from trends in growing season (May-August) precipitation and maximum and minimum temperatures between 2021 and 2100, simulated by the seven NA-CORDEX RCMs. First, we calculated the linear trends for tasmin, tasmax, and pr, and then we computed the difference between the trend values for 2100 and 2021 to estimate the potential range of changes. Total precipitation could potentially increase by $10 \%$, while minimum and maximum temperature could potentially increase by approximately $5.1^{\circ} \mathrm{C}$ and $4.9^{\circ} \mathrm{C}$, respectively. 
These changes in mean values will be advantageous, although any increases in crop productivity could be offset by the impacts of extreme weather events, which are not considered for the assessing of the value of arable agricultural land.

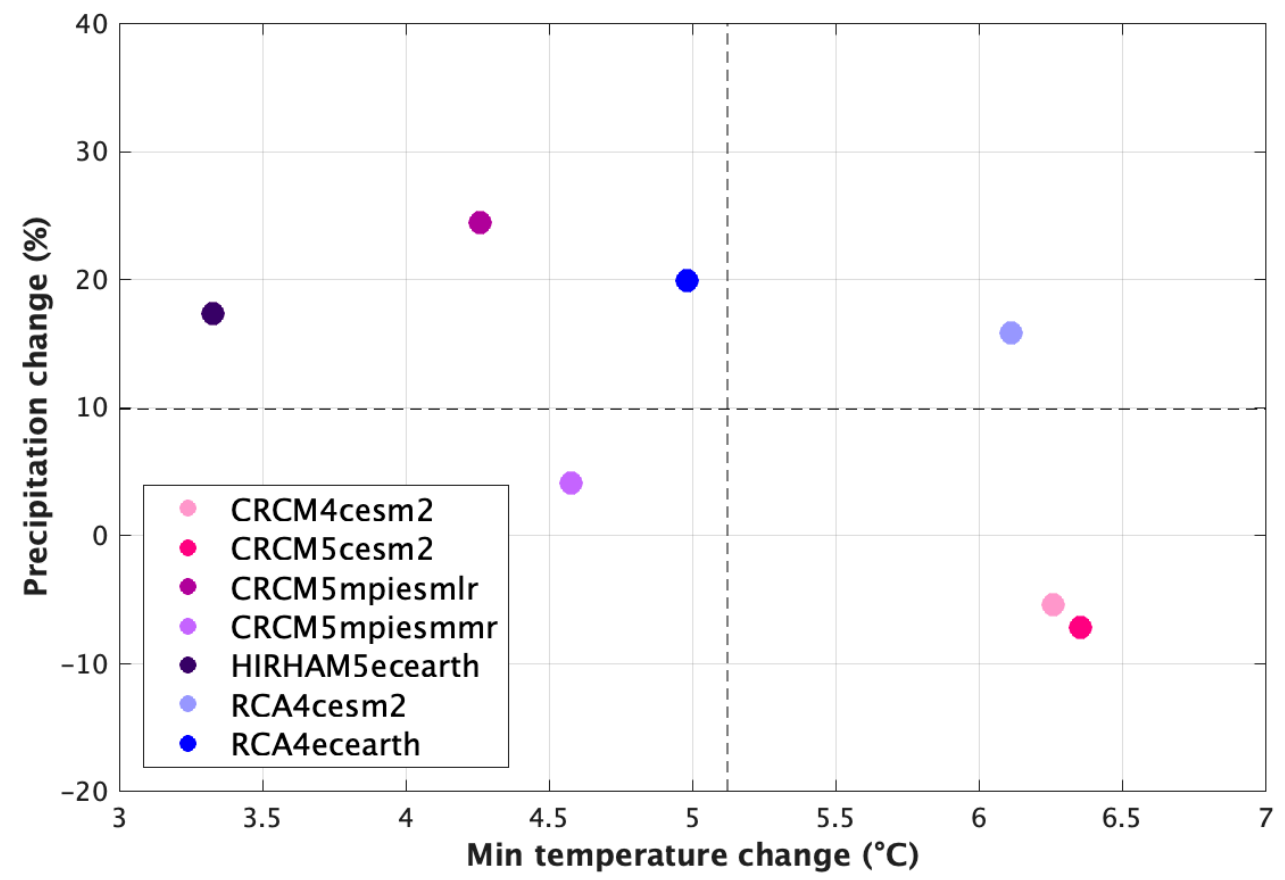

Figure 18. Projected changes from trends in growing season (May-August) minimum temperature and total precipitation (each colored circle represents a different RCM, and the dashed lines represent average climatic changes).

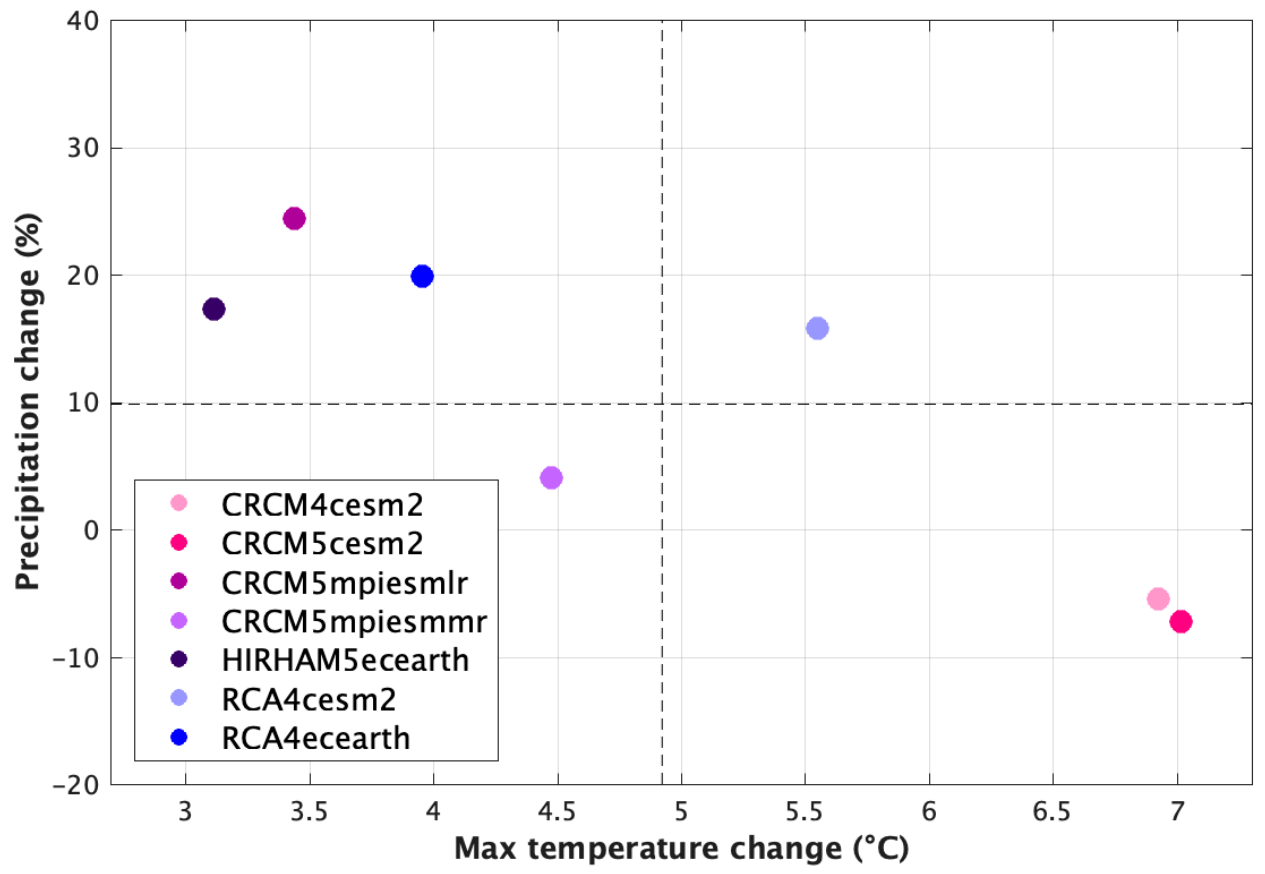

Figure 19. Projected changes from trends in growing season (May-August) maximum temperature and total precipitation (each colored circle represents a different RCM, and the dashed lines represent average climatic changes). 


\section{Discussion}

This study established the geographic patterns and trends in climate and wheat yield over an extensive area, Saskatchewan's arable agricultural land, and for a large number of weather variables, including the length of GDDs and FFDs, annual and seasonal averages of maximum and minimum temperatures, and total precipitation for 1979-2016. The results revealed that hydroclimatic variability across Saskatchewan's arable agricultural landscape is strongly correlated with wheat yield in all soil zones, with climate variables sharing up to $75 \%$ of the annual variance in wheat yield. Historical climate trends (1885-2016) show an increase in growing season minimum temperature and decrease in maximum temperature throughout all soil zones, and large precipitation variability, although with a recent increasing trend. These full weather records provide a better understanding of where the shorter record (1979-2016) falls in terms of long-term trends, natural climatic variability, and decadal cycles.

Analysis of the interpolated data revealed that the strongest trends were for minimum winter temperatures. However, regression analysis of interpolated weather and wheat yield data for 1979-2016 and 296 RMs throughout six soil zones indicated that summer precipitation, followed by spring precipitation and maximum summer temperature, have had the strongest influence on wheat yield across Saskatchewan's arable agricultural zone for the last 38 years. Each unique regression equation for the RMs did a fairly good job at predicting the annual wheat yield, as the differences between average and predicted yield were negligible and only minimally overestimated or underestimated. The linear models minimally overestimated yield during some drought years, due to the nonlinear relationship of precipitation and yield, whereby very low precipitation can result in crop failure (i.e., zero yield).

Our investigation of regional climate change also included RCM projections (2021-2100) of increasing maximum and minimum temperatures and total precipitation. These projected climate changes suggest the potential for higher crop productivity as predicted by crop modeling studies $[7,8]$, although neither our study nor most of the crop modeling research account for the changes in the severity of extreme weather on crop yield.

\section{Conclusions}

The objective of our study was to consider whether the provincial agency responsible for assessing the value of agricultural land should adjust the climate rating in their arable land assessment model. We examined recent climate changes and the statistical relationship between weather variables and wheat yield, in contrast to research on the numerical simulation and prediction of crop yields. Because climate and wheat yield are changing more or less consistently throughout all soil zones within Saskatchewan's arable agricultural landscape, modifying the climate factor ratings in one area compared to another is not warranted at this time. The strongest historical climate trends are for minimum winter temperature, but according to the correlation and regression analyses, this weather variable did not influence wheat yield significantly for 1979-2016 ( $p>0.05)$. Hence, there is no evidence that crop yields are benefiting from a warmer winter. According to the climate and wheat yield data for 38 years, there is no evidence of significant increases in growing season precipitation and temperature, and thus, the current climate ratings in place are reasonable. However, with further warming of the climate of Saskatchewan, modifications to the climate rating in the land assessment model could be considered for the revaluation due in 2025. Due to a high degree of uncertainty in the projections of temperature and highly variable precipitation [33], we cannot speculate as to when the change in these variables will result in a change in crop yields that necessitates a change in the land assessment climate factor rating. However, based on the recent and projected climate changes documented within this paper, at some point a modification in the climate factor rating will be justified, and thus, we suggest that there should be periodic re-evaluation of the climate factor rating. Future analyses should consider the impacts of extreme weather on crop yield, as research suggests that a warming climate is amplifying the severity of extreme weather events (i.e., droughts, floods, and heat waves [34]). Any future analyses at high spatial and temporal resolution (i.e., daily and $10 \mathrm{~km}$ ) may 
also consider bias correction of the weather data to determine to what extent interpolation methods can smooth climate extremes (i.e., minimum and maximum temperature, and precipitation) [27].

Author Contributions: Conceptualization, S.A.K. and D.J.S.; methodology, S.A.K.; data curation, S.A.K. and Y.A.; formal analysis, S.A.K.; investigation, S.A.K.; writing-original draft preparation, S.A.K.; writing-review and editing, D.J.S.; visualization, S.A.K. and Y.A.; supervision, D.J.S.; funding acquisition, D.J.S.

Funding: This research was funded by MITACS Accelerate, Information Systems Management (ISM) Canada, and the Saskatchewan Assessment Management Agency (SAMA).

Acknowledgments: Weather station data were provided by ISM Canada, and the Saskatchewan Crop Insurance Corporation (SCIC) provided wheat yield data. We thank Steve Suchan, Shaun Cooney, Kim Hardy, Naiomi Lynn, Travis Juffinger, and Joe Lovick for their guidance and advice. We thank Sheena Hatcher for assistance with data preparation, and the three anonymous reviewers for their helpful comments and suggestions.

Conflicts of Interest: The authors declare no conflict of interest. The authors acknowledge that the funders had a role in the design of the study and provided data for the analysis.

\section{References}

1. Statistics Canada. Total Area of Farms and Use of Farm Land, Historical Data. 2016. Available online: https: / / www150.statcan.gc.ca/t1/tbl1/en/tv.action?pid=3210015301\&pickMembers\%5B0\%5D=1. 9\&pickMembers\%5B1\%5D=3.2 (accessed on 15 January 2019).

2. Saskatchewan Trade \& Export Partnership. State of Trade Report. 2017. Available online: https: / www.sasktrade.com/public/uploads/Exporter\%20Resources/Saskatchewan\%20State\% 20of\%20Trade\%202017.pdf (accessed on 15 January 2019).

3. Wheaton, E.; Kulshreshtha, S. Agriculture. In The New Normal: The Canadian Prairies in a Changing Climate; Sauchyn, D.J., Diaz, H., Kulshreshtha, S., Eds.; CPRC Press: Regina, SK, Canada, 2010; Chapter 7.

4. Bradshaw, B.; Dolan, H.; Smit, B. Farm-Level Adaptation to Climatic Variability and Change: Crop Diversification in the Canadian Prairies. Clim. Chang. 2004, 67, 119-141. [CrossRef]

5. Campbell, I.D.; Durant, D.G.; Hunter, K.L.; Hyatt, K.D. Food Production. In Canada in a Changing Climate: Sector Perspectives on Impacts and Adaptation; Warren, F.J., Lemmen, D.S., Eds.; Government of Canada: Ottawa, ON, Canada, 2014; pp. 99-134.

6. Chipanshi, A.; Zhang, Y.; Kouadio, L.; Newlands, N.; Davidson, A.; Hill, H.; Warren, R.; Qian, B.; Daneshfar, B.; Bedard, F.; et al. Evaluation of the Integrated Canadian Crop Yield Forecaster (ICCYF) model for in-season prediction of crop yield across the Canadian agricultural landscape. Agric. For. Meteorol. 2015, 206, 137-150. [CrossRef]

7. Poudel, S. Economic Impacts of Climate Change and Weather Extremes on Canadian Prairie Mixed Farms. Ph.D. Thesis, Department of Bio-Resource Policy, University of Saskatchewan, Saskatoon, SK, Canada, January 2016.

8. Qian, B.; Gameda, S.; Zhang, X.; De Jong, R. Changing growing season observed in Canada. Clim. Chang. 2012, 112, 339-353. [CrossRef]

9. Bonsal, B.; Cuell, C.; Wheaton, E.; Sauchyn, D.; Barrow, E. An assessment of historical and projected future hydro-climatic variability and extremes over southern watersheds in the Canadian Prairies. Int. J. Climatol. 2017, 37, 3934-3948. [CrossRef]

10. Wheaton, E.; Sauchyn, D.; Bonsal, B. Future Possible Droughts. In Vulnerability and Adaptation to Drought: The Canadian Prairies and South America; Diaz, H., Hurlbert, M., Warren, J., Eds.; University of Calgary Press: Calgary, AB, Canada, 2016; Chapter 3; 387p.

11. Herrington, R.; Johnson, B.; Hunter, F. Responding to Global Climate Change in the Prairies. In Canada Country Study: Climate Impacts and Adaptations; Environment Canada: Ottawa, ON, Canada, 1997; Volume 3, 270p.

12. Kharin, V.V.; Zwiers, F.W.; Zhang, X.; Hegerl, G.C. Changes in Temperature and Precipitation Extremes in the IPCC ensemble of Global Couple Model Simulations. J. Clim. 2007, 20, 1419-1444. [CrossRef]

13. Weber, M.; Hauer, G. A Regional Analysis of Climate Change Impacts on Canadian Agriculture. Can. Public Pol. 2003, 29, 163-180. [CrossRef]

14. Qian, B.; De Jong, R.; Warren, R.; Chipanshi, A.; Hill, H. Statistical spring wheat yield forecasting for the Canadian Prairie Provinces. Agric. For. Meteorol. 2009, 149, 1022-1031. [CrossRef] 
15. Saskatchewan Assessment Management Agency (SAMA). Methods of Assessment. 2018. Available online: https: / / www.sama.sk.ca/property-owner-services/understanding-assessment/methods-assessment (accessed on 20 December 2018).

16. Sauchyn, D. Prairie Climate Trends and Variability. In The New Normal: The Canadian Prairies in a Changing Climate; Sauchyn, D.J., Diaz, H., Kulshreshtha, S., Eds.; CPRC Press: Regina, SK, Canada, 2010; Chapter 3.

17. Sauchyn, D.J.; Xongchao, Y. Evaluation of the Climatic Factor in Rural Land Assessment; Final Report to the Saskatchewan Assessment and Management Agency; Report; University of Regina: Saskatchewan, SK, Canada, 1990; p. 91.

18. Lobel, D.B.; Schlenker, W.; Costa-Roberts, J. Climate trends and global crop production since 1980. Science 2011, 333, 616-620. [CrossRef]

19. Kutcher, H.R.; Warland, J.S.; Brandt, S.A. Temperature and precipitation effects on canola yields in Saskatchewan, Canada. Agric. For. Meteorol. 2010, 150, 160-165. [CrossRef]

20. Lobell, D.B.; Burke, M.B. On the use of statistical models to predict crop yield responses to climate change. Agric. For. Meteorol. 2010, 150, 1443-1452. [CrossRef]

21. Mkhabela, M.S.; Bullock, P.; Raj, S.; Wang, S.; Yang, Y. Crop yield forecasting on the Canadian Prairies using MODIS NDVI data. Agric. For. Meteorol. 2011, 151, 385-393. [CrossRef]

22. He, Y.; Wei, Y.; DePauw, R.; Qian, B.; Lemke, R.; Singh, A.; Cuthbert, R.; McConkey, B.; Wang, H. Spring wheat yield in the semiarid Canadian prairies: Effects of precipitation timing and soil texture over recent 30 years. Field Crop Res. 2013, 149, 329-337. [CrossRef]

23. Robertson, S.M.; Jeffrey, S.R.; Unterschultz, J.R.; Boxall, P.C. Estimating yield response to temperature and identifying critical temperatures for annual crops in the Canadian prairie region. Can. J. Plant Sci. 2013, 93, 1237-1247. [CrossRef]

24. Meng, T.; Carew, R.; Florkowski, W.J.; Klepacka, A.M. Analyzing Temperature and Precipitation Influences on Yield Distributions of Canola and Spring Wheat in Saskatchewan. Bull. Am. Meteorol. 2017, 56, 897-913. [CrossRef]

25. Adjusted and Homogenized Canadian Climate Data (AHCCD). 2017. Available online: http://ec.gc.ca/ dccha-ahccd/default.asp?lang=En\&n=B1F8423 (accessed on 5 November 2018).

26. McKenney, D.W.; Hutchinson, M.F.; Papadopol, P.; Lawrence, K.; Pedlar, J.; Campbell, K.; Milewska, W.; Hopkinson, R.F.; Price, D.; Owen, T. Customized spatial climate models for North America. Bull. Am. Meteorol. 2011, 92, 1611-1622. [CrossRef]

27. Newlands, N.K.; Davidson, A.; Howard, A.; Hill, H. Validation and inter-comparison of three methodologies for interpolating daily precipitation and temperature across Canada. Environmetrics 2011, 22, 205-223. [CrossRef]

28. Quiring, S.M.; Papakryiakou, T.N. An evaluation of agricultural drought indices for the Canadian Prairies. Agric. For. Meteorol. 2003, 118, 49-62. [CrossRef]

29. Campbell, C.A.; Selles, F.; Zentner, R.P.; McConkey, B.G.; Brandt, S.A.; McKenzie, R.C. Regression model for predicting yield of hard red spring wheat grown on stubble in the semiarid prairie. Can. J. Plant Sci. 1997, 77, 43-52. [CrossRef]

30. Von Storch, H.; Zwiers, F.W. Statistical Analysis in Climate Research; Cambridge University Press: Cambridge, UK, 1999; 484p.

31. Burn, D.H.; Hesch, N.M. A Comparison of Trends in Potential and Pan Evaporation for the Canadian Prairies. Can. Water Resour. J. 2006, 31, 173-184. [CrossRef]

32. Gameda, S.; Qian, B.; Campbell, C.A.; Desjardins, R.L. Climatic trends associated with summer fallow in the Canadian Prairies. Agric. For. Meteorol. 2007, 142, 170-185. [CrossRef]

33. Barrow, E.; Sauchyn, D. Uncertainty in climate projections and time of emergence of climate signals in western Canada. Int. J. Climatol. in press.

34. Intergovernmental Panel on Climate Change (IPCC). Climate Change 2013: The Physical Science Basis. Contribution of Working Group I to the Fifth Assessment Report of the Intergovernmental Panel on Climate Change. 2013. Available online: https://www.ipcc.ch/report/ar5/wg1/ (accessed on 15 November 2018).

(C) 2019 by the authors. Licensee MDPI, Basel, Switzerland. This article is an open access article distributed under the terms and conditions of the Creative Commons Attribution (CC BY) license (http:/ / creativecommons.org/licenses/by/4.0/). 